Check for updates

Cite this: RSC Adv., 2019, 9, 31133

Received 21st June 2019

Accepted 9th September 2019

DOI: $10.1039 / c 9 r a 04654 b$

rsc.li/rsc-advances

\section{Properties and degradation of castor oil-based fluoridated biopolyurethanes with different lengths of fluorinated segments}

\author{
Jia-Wun Li, (D) a Yung-Hsin Cheng, ${ }^{a}$ Hsun-Tsing Lee, ${ }^{b}$ Wen-Chin Tsen, ${ }^{c}$ \\ Chih-Wei Chiu (ID *a and Maw-Cherng Suen (D) *d
}

\begin{abstract}
To develop a durable, biodegradable polymer, this study successfully synthesized a castor-oil-based prepolymer by using methylene diphenyl diisocyanate as a hard segment, polycaprolactone as a soft segment, and castor oil as a functional monomer. We added perfluorinated alkyl segments with varying chain lengths into the castor-oil-based polymer to synthesize castor-oil-based fluoridated biopolyurethanes (FCOPUs) with different fluorinated segment lengths. The castor-oil-based polyurethanes with different fluorinated segment lengths had similar molecular weights, which enabled accurate analysis of the effect of the lengths of fluorinated segments on FCOPUs. Nuclear magnetic resonance (NMR) was used to perform ${ }^{1} \mathrm{H} N M R,{ }^{19} \mathrm{~F} N M R,{ }^{19} \mathrm{~F}-{ }^{19} \mathrm{~F}$ COSY, ${ }^{1} \mathrm{H}-{ }^{19} \mathrm{~F}$ COSY, and HMBC analyses on the FCOPU structures. The results of Fourier transform infrared spectroscopy and $\mathrm{X}$-ray photoelectron spectroscopy curve fitting verified the interaction between $\mathrm{C}-\mathrm{F} \cdots \mathrm{H}-\mathrm{N}$ and $\mathrm{C}-\mathrm{F} \cdots \mathrm{C}=\mathrm{O}$. This interaction increased as the fluorinated segments became longer. Regarding the thermal properties of the FCOPUs, the thermogravimetric analysis, differential scanning calorimetry, and dynamic mechanical analysis results revealed that long fluorinated segments were associated with increased thermal stability in the FCOPUs. The atomic force microscopy and tensile strength test suggested that long fluorinated segments contained in the FCOPUs increased the degree of phase separation and tensile strength in FCOPUs. Finally, we dipped the FCOPUs in a $3 \mathrm{wt} \% \mathrm{NaOH}$ solution, calculated the weight loss of the FCOPUs, and observed their surface structure by using scanning electron microscopy.
\end{abstract}

\section{Introduction}

Since the 1950s, human beings have produced approximately 8.3 billion tons of plastics, most of which do not biodegrade in the environment; with increasing environmental awareness, people have become more aware of the damaging effects of plastics on the environment. ${ }^{\mathbf{1 , 2}}$ Accordingly, degradable polymers have been widely studied, including polylactic acid (PLA) ${ }^{3}$ polyhydroxybutyrate (PHB), ${ }^{4}$ petroleum-based polymers (e.g., polycaprolactone [PCL] and poly[butylene] succinate [PBS]),,$^{5-7}$ and vegetable oils. Even though degradable polymers might appear to be ideal from an environmental perspective, the

${ }^{a}$ Department of Materials Science and Engineering, National Taiwan University of Science and Technology, No. 43, Keelung Rd., Sec. 4, Da'an Dist, Taipei, 10607, Taiwan, ROC. E-mail: cwchiu@mail.ntust.edu.tw; Fax: +886-2-2737-6544; Tel: +886-2-2737-6521

${ }^{b}$ Department of Materials Science and Engineering, Vanung University, Jongli, Taoyuan, 32061, Taiwan, ROC

${ }^{c}$ Department of Fashion and Design, Lee-Ming Institute of Technology, New Taipei City, 24305, Taiwan, ROC

${ }^{d}$ Department of Fashion Business Administration, Lee-Ming Institute of Technology, No.22, Sec.3, Tailin Rd. Taishan Dist., New Taipei City, 24305, Taiwan, ROC. E-mail: sunmc0414@gmail.com; Tel: +886-2-2909-7811 ext. 1101 durability of degradable polymers requires further examination. ${ }^{8}$ Vegetable oils are renewable, low-cost, and chemically modifiable resources. ${ }^{9}$ Castor oil (CO) is a vegetable oil that is extracted from castor beans, contains three hydroxyl groups, can be used as a bifunctional monomer, and thus has been applied in preparing various biodegradable polymers. ${ }^{\mathbf{1 0 , 1 1}}$

Thermoplastic polyurethane (PU) is a block copolymer that is often synthesized with diol (soft segment), diisocyanate (hard segment), and chain extenders. ${ }^{12,13}$ The incompatibility between soft and hard segments leads to microphase separation, and the level of microphase separation is closely related to the tensile strength of PU. ${ }^{\mathbf{1 4 , 1 5}}$ Studies have discussed factors causing microphase separation in PU, such as hydrogen bonds (HBs) ${ }^{\mathbf{1 6 , 1 7}}$ and the ratio of soft and hard segments. ${ }^{18,19}$ Thermoplastic PU exhibits high strength, toughness, and wearability, and has properties of both plastics and elastomers $;^{\mathbf{2 0 , 2 1}}$ thus it can be used in various industries. Accordingly, the present study focused on biodegradable PU. Relevant studies have used castor oil as the soft segment of PU, ${ }^{22-25}$ but the crosslink effect of castor oil leads to excessive stiffness of castor-oil-based PU, which decreases the ductility of conventional PU. A scholar used castor oil and PCL as the soft segment of castor-oil-based PU 
to maintain its ductility. ${ }^{26} \mathrm{~A}$ paper examined the degradability of PCL in acid and alkaline environments and revealed that PCL showed higher degradability in an alkaline solution than in an acid solution. ${ }^{27}$ Therefore, the present study was aimed at increasing the alkaline resistance of PCL-based polyurethane. The known interchain interactions of organofluorines were $\pi-\pi_{\mathrm{F}}, \mathrm{C}-\mathrm{F} \cdots \mathrm{H}, \mathrm{F} \cdots \mathrm{F}, \mathrm{C}-\mathrm{F} \cdots \pi_{\mathrm{F}}, \mathrm{C}-\mathrm{F} \cdots \pi, \mathrm{C}-\mathrm{F} \cdots$ $\mathrm{M}^{+}, \mathrm{C}-\mathrm{F} \cdots \mathrm{C}=\mathrm{O}$ and anion $-\pi_{\mathrm{F}}{ }^{28}$ So, when the organofluorines were introduced to polyurethane, due to these interchain interactions could increase the amount of PCLbased polyurethane intermolecular force, so that the molecular segment was more stable. The present study used castor oil and PCL as the soft segment of PU, used a fluorinated chain extender to strengthen the interactions in PU, and aimed to increase the alkaline resistance of PCL and increase the durability of biodegradable PU. A study revealed that high fluorine content in PU indicated a high level of microphase separation of PU, and elevated tensile strength. ${ }^{29}$ Most relevant studies have examined fluorinated PU by changing the content of fluorinated chain extenders; changing the ratio of soft segment content to fluorinated chain extender content may result in different ratios of soft segments to hard segments, which may affect the properties of PU. ${ }^{30}$ To our knowledge, no research has discussed, with a constant $R$ value ( $\mathrm{NCO}: \mathrm{OH}$ ), the influence of fluorine on PU; therefore, the present study changed the chain length of a fluorinated chain extender to investigate the effect of such length on PU.

This study synthesized castor-oil-based fluoridated biopolyurethanes (FCOPUs) of varying chain lengths by using perfluorinated alkyl chains of varying lengths as the chain extender, methylene diphenyl diisocyanate (MDI) as the hard segment, PCL as the soft segment, and castor oil as the functional monomer. Moreover, we investigated the variance of molecular weight variance of FCOPUs by using gel permeation chromatography and examined the thermal properties of FCOPUs by using the thermogravimetric analysis (TGA), differential scanning calorimetry (DSC), and dynamic mechanical analysis (DMA). Furthermore, Fourier transform infrared spectroscopy (FTIR), X-ray photoelectron spectroscopy (XPS) were used to observe the changes of interactions in FCOPUs, their structures were confirmed through nuclear magnetic resonance (NMR), and a tensile testing machine and atomic force microscopy (AFM) were used to discuss the tensile strength and phase separation of FCOPUs. Finally, we dipped the FCOPUs in a NaOH solution to first calculate the weight loss of the FCOPUs and then observe the details of surface structure using scanning electron microscopy (SEM).

\section{Experimental}

\subsection{Materials}

2,2,3,3,4,4,5,5-Octafluoro-1,6-hexanediol, 2,2,3,3,4,4,5,5,6,6,7,7dodecafluoro-1,8-octanediol and 2,2,3,3,4,4,5,5,6,6,7,7,8,8,9,9hexadecafluoro-1,10-decanediol were purchased from Matrix Scientific. 4,4'-Diphenylmethane diisocyanate (MDI), polycaprolactone diol (PCL, $\left.M_{\mathrm{w}}=530\right)$, and dibutyltin dilaurate (DBTDL) were purchased from Aldrich. $N, N$-dimethylacetamide
(DMAc) was obtained from Mallinckrodt Chemicals. Castor oil (CO) was purchase from Alfa Aesar.

\subsection{Synthesis of FCOPUs}

A two-step process was used to polymerize the FCOPUs. First, MDI, PCL, castor oil and $N, N$-dimethylacetamide (DMAc) were added to a $500 \mathrm{~mL}$ four-neck reaction flask and heated to $80{ }^{\circ} \mathrm{C}$ using a heating mantle. After 2 to 3 drops of dibutyltin dilaurate were added, the solution was mixed using a mechanical stirrer at $10 \mathrm{rpm}$, and PU prepolymers were formed after $2 \mathrm{~h}$ of reaction. In the second step, the chain extenders were dissolved in DMAc and slowly dripped into the reaction flask, and the reaction was continued for $2 \mathrm{~h}$ (Scheme 1). The obtained FCOPUs solution was subjected to vacuum defoaming for $2 \mathrm{~h}$, after which it was poured into a serum bottle and stored in a refrigerator for 1 day. Finally, the FCOPUs solution was poured into a Teflon plate and dried in a temperature-programmable circulating oven for $8 \mathrm{~h}$. The formula, symbols, and contents of the hard and soft segments for the FCOPUs films are shown in Table 1. The contents of the hard and soft segments were calculated according to eqn (2.1) and (2.2).

$$
\text { Hard segment content }=\frac{W_{\text {hard }}+W_{\text {extender }}}{W_{\text {hard }}+W_{\text {soft }}+W_{\text {extender }}} \times 100
$$

Soft segment content $\left(\mathrm{wt}^{\mathrm{o}} \%\right)$

$$
=100 \%-\text { hard segment content }(\mathrm{wt} \%)
$$

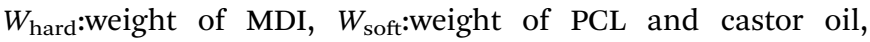
$W_{\text {extender}}$ :weight of extender.

In this study, the sample names of the FCOPUs were coded as \#FCOPU, where "\#" refers to the number of fluorine elements in extender, e.g., 12FCOPU. In order to evaluate the influence of fluorinated chain in FCOPUs on degradability, we prepared the control polymer additionally. The purpose of this formula was to replace the amount of fluorinated chain extender by PCL, the whole NCO : OH was still $1: 1$.

\subsection{Gel permeation chromatography (GPC)}

Gel permeation chromatography (GPC) was carried in THF solution using polystyrene standards for calibration with Waters ACQUITY APC with $1 \times$ ACQUITY APC XT 200 + $1 \times$ ACQUITY APC XT 450 columns using a ACQUITY refractive index detector. The flow rate is set as a $0.8 \mathrm{~mL} \mathrm{~min}^{-1}$ in $45{ }^{\circ} \mathrm{C}$.

\subsection{Fourier transform infrared spectroscopy (FTIR)}

Fourier transform infrared spectroscopy measurements were performed on a Digilab (Hopkinton, MA, USA) (model (FTS1000)). The spectra of the samples were obtained by averaging 16 scans in a range of 4000 to $650 \mathrm{~cm}^{-1}$ with a resolution of $2 \mathrm{~cm}^{-1}$.

\section{$2.5{ }^{1} \mathrm{H}$ nuclear magnetic resonance (NMR) spectrometer}

The ${ }^{1} \mathrm{H}$ NMR (in DMSO-d6) spectra of the specimens were measured by a Bruker Avance 300 spectrometer $(300 \mathrm{MHz})$. 


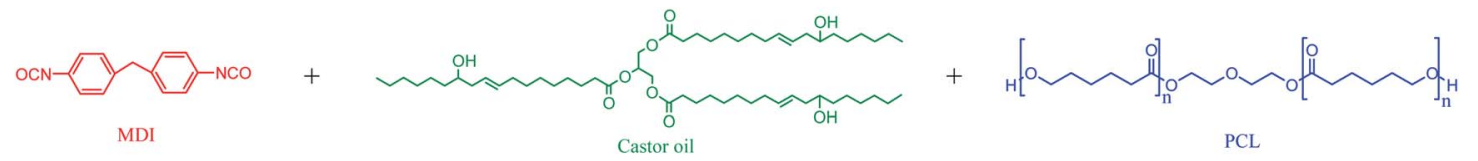

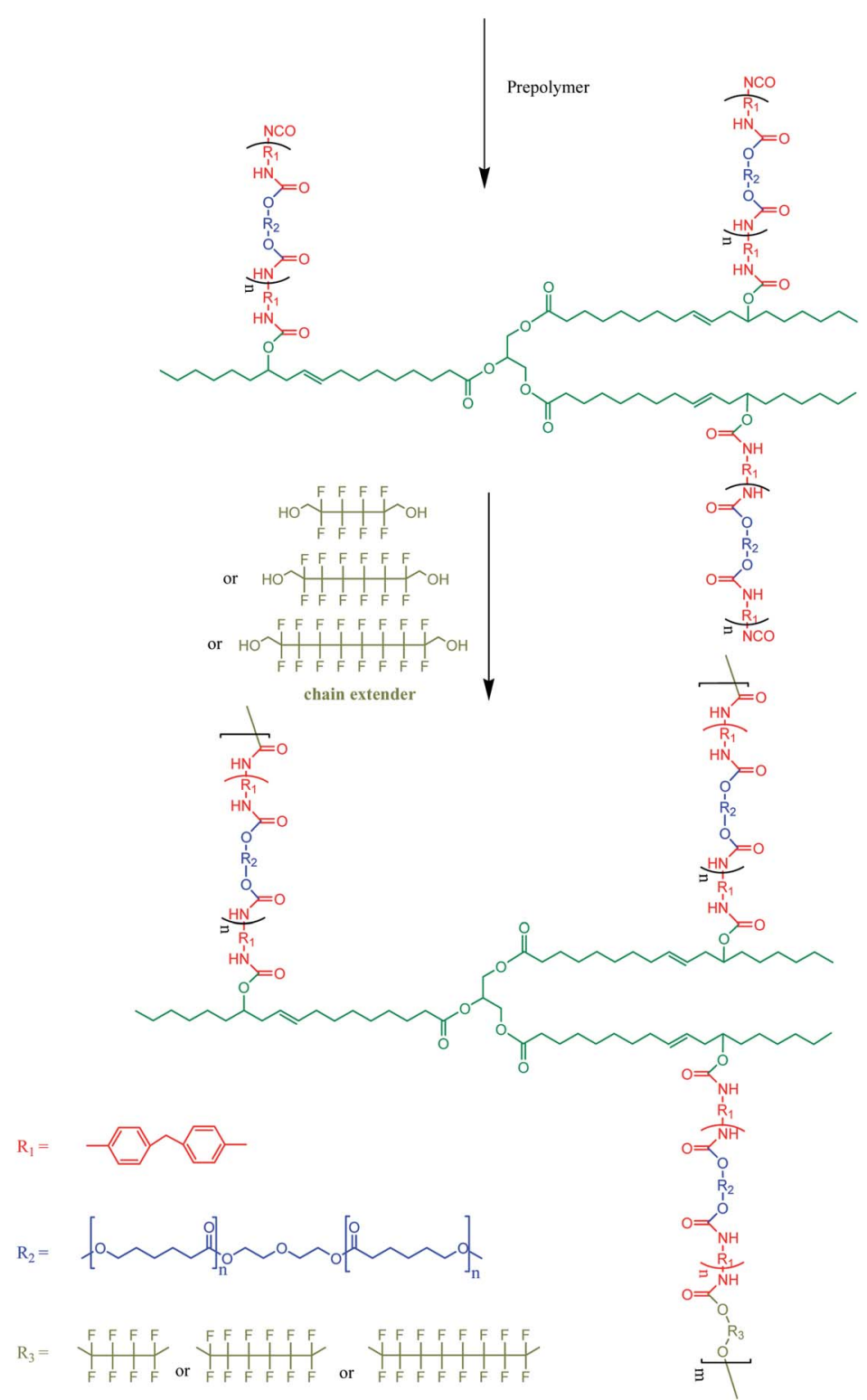

Scheme 1 Formula for the FCOPUs.

\section{$2.6{ }^{19} \mathrm{~F}$ NMR spectrometer}

The ${ }^{19} \mathrm{~F}$ NMR spectra of the polymers were recorded using a Bruker Avance IIIHD $400 \mathrm{~Hz}$ spectrometer using DMSO-d6 as a solvent and tetramethylsilane as an internal standard.

\subsection{X-ray photoelectron spectroscopy (XPS)}

The X-ray photoelectron spectroscopy (XPS) measurements were carried out using a Thermo Fisher Scientific (VGS) spectrometer (Waltham, MA, USA). An Al K $\alpha$ anode was used as the X-ray source (1486.6 eV), and a binding energy range of 0 to $1400 \mathrm{eV}$

Table 1 Formulas of the FCOPUs

\begin{tabular}{|c|c|c|c|c|c|c|}
\hline Designation & MDI (mole) & CO (mole) & PCL (mole) & Extender (mole) & Hard segment (wt\%) & Soft segment (wt\%) \\
\hline 8FCOPU & 4 & 0.4 & 3.2 & 0.2 & 33.73 & 66.27 \\
\hline $12 \mathrm{FCOPU}$ & 4 & 0.4 & 3.2 & 0.2 & 34.16 & 65.84 \\
\hline
\end{tabular}


was selected for the analysis. The binding energies were calibrated to the $\mathrm{C} 1 \mathrm{~s}$ internal standard with a peak at $284.8 \mathrm{eV}$. The high resolution $\mathrm{C}$ 1s spectra were decomposed by fitting a Gaussian function to an experimental curve using a nonlinear regression.

\subsection{Surface roughness analysis}

Scanning was performed using a Bruker Dimension Icon atomic force microscope, which is generally operated in two imaging modes: tapping and contact. The tapping mode was used in this study, and the tip of the oscillation probe cantilever made only intermittent contact with the sample. Regarding the phase of the sine wave that drives the cantilever, the phase of the tip oscillation is extremely sensitive to various sample surface characteristics; therefore, the topography and phase images of a sample's surface can be detected.

\subsection{Thermogravimetric analysis (TGA)}

Thermogravimetric analysis was performed on a TA instruments Q-500 (New Castle, DE, USA). The samples (5-8 mg) were heated from room temperature to $700{ }^{\circ} \mathrm{C}$ under nitrogen at a rate of $10^{\circ} \mathrm{C} \mathrm{min}^{-1}$.

\subsection{Differential scanning calorimetry (DSC)}

Differential scanning calorimetry was performed on a PerkinElmer differential scanning calorimetry (model DSC 6000). The samples were sealed in aluminum pans with a perforated lid. The scans $\left(-50\right.$ to $\left.50{ }^{\circ} \mathrm{C}\right)$ were performed at a heating rate of $10^{\circ} \mathrm{C} \min ^{-1}$ under nitrogen purging. The glass transition temperatures $\left(T_{\mathrm{g}}\right)$ were located as the midpoints of the sharp descent regions in the recorded curves. The melting points were recorded as the peak maximum of the endothermic transition in the second scan. Approximately 5-8 $\mathrm{mg}$ of the samples were used in all of the tests.

\subsection{Dynamic mechanical analysis (DMA)}

Dynamic mechanical analysis was performed on DMA Q800 machine (TA Instruments) at $1 \mathrm{~Hz}$ with a $5 \mu \mathrm{m}$ amplitude over a temperature range of -50 to $50{ }^{\circ} \mathrm{C}$ at a heating rate of $3^{\circ} \mathrm{C} \mathrm{min}^{-1}$. Specimens with dimensions of $35.6 \times 12.7 \times 2 \mathrm{~mm}^{3}$ were used in these tests. The dynamic glass transition temperature was taken as the peak temperature of the glass transition region in the $\tan \delta$ curve.

\subsection{Stress-strain testing}

Tensile strength and elongation at break were measured using a universal testing machine (CY-6040A8). Testing was conducted with ASTM D638. The dimension of the film specimen was $45 \mathrm{~mm} \times 8 \mathrm{~mm} \times 0.2 \mathrm{~mm}$.

\subsection{Hydrolytic degradation tests}

Hydrolytic degradation evaluation of the specimens was conducted in a $3 \%$ aqueous $\mathrm{NaOH}$ solution at $45{ }^{\circ} \mathrm{C}$. The specimens with dimensions of $2 \times 2 \mathrm{~cm}^{2}$ were tested for various days, washed with distilled water and dried completely in a vacuum oven at $70{ }^{\circ} \mathrm{C}$ for $3 \mathrm{~h}$. The degree of degradation was determined from the weight loss in eqn (2.3):

$$
\text { Weight loss }=\frac{W_{0}-W_{t}}{W_{0}}
$$

where $W_{0}$ is the dry weight before degradation, and $W_{t}$ is the dry weight at time $t$.

\subsection{Morphology analysis}

Morphology of the specimens after hydrolytic degradation was observed by using a high resolution Field-Emission Scanning Electron Microscope (FESEM), model JSM-6500F. Specimens of $2 \times 2 \mathrm{~cm}^{2}$ were fixed on a sample holder using conductive adhesive tape and were then coated with a thin layer of platinum to improve image resolution. The samples were photographed with $1.00 \mathrm{~K}$ magnification.

\section{Results and discussion}

\subsection{Gel permeation chromatography analysis}

The gel permeation chromatography curves of the FCOPUs are depicted in Fig. 1; according to the molecular weight distribution results, each of the FCOPUs produced using a chain extender with varying chain lengths exhibits a single peak and does not have any small molecule peaks, indicating complete reaction between the chain extender and the prepolymers. Table 2 presents the calculated molecular weights of FCOPUs and shows that an increased chain length of the fluorinated chain extender is associated with a slightly increased retention time, very often the fluorinated polymers may have interaction with GPC columns which also increased the retention time. Besides, this result of molecular weight might because a long fluorinated chain extender has a large molecular weight, which leads to phenomenon such as decreased activity and increased steric hindrance, thus decreasing the molecular weights of FCOPUs. The molecular weight distribution value (polydispersity index [PDI] = weight - average molecular weight/number - average molecular weight) of all samples were shown to be 1.6, which suggested that the molecular weight distributions of all samples were similar to one another. Specifically, the effect of molecular weight distribution on the properties of FCOPUs would not be substantial in the study's subsequent experiment; such a comparison result among the FCOPUs enhanced our discussion of the effect of chain extender length on FCOPU properties.

\subsection{Fluorine-19 NMR}

To ensure that fluorinated chain extender was linked to the FCOPUs, the relative positions in a fluorine-19 NMR spectrum must be determined first. This study used the 12FCOPU as the sample for analysis; the fluorinated chain extender for the 12FCOPU contained three different types of symmetric $\mathrm{CF}_{2}$, namely (A) $\mathrm{O}=\mathrm{C}-\mathrm{O}-\mathrm{CF}_{2}{ }^{*}-\mathrm{CF}_{2}$, (B) $\mathrm{O}-\mathrm{CF}_{2}-\mathrm{CF}_{2}{ }^{*}-\mathrm{CF}_{2}$, and (C) $\mathrm{CF}_{2}-\mathrm{CF}_{2}-\mathrm{CF}_{2}{ }^{*}-\mathrm{CF}_{2}$. Fig. 2 illustrates the ${ }^{19} \mathrm{~F}-{ }^{19} \mathrm{~F}$ NMR of the 12FCOPU and reveals three absorption peaks at $-119.81 \mathrm{ppm}$, 


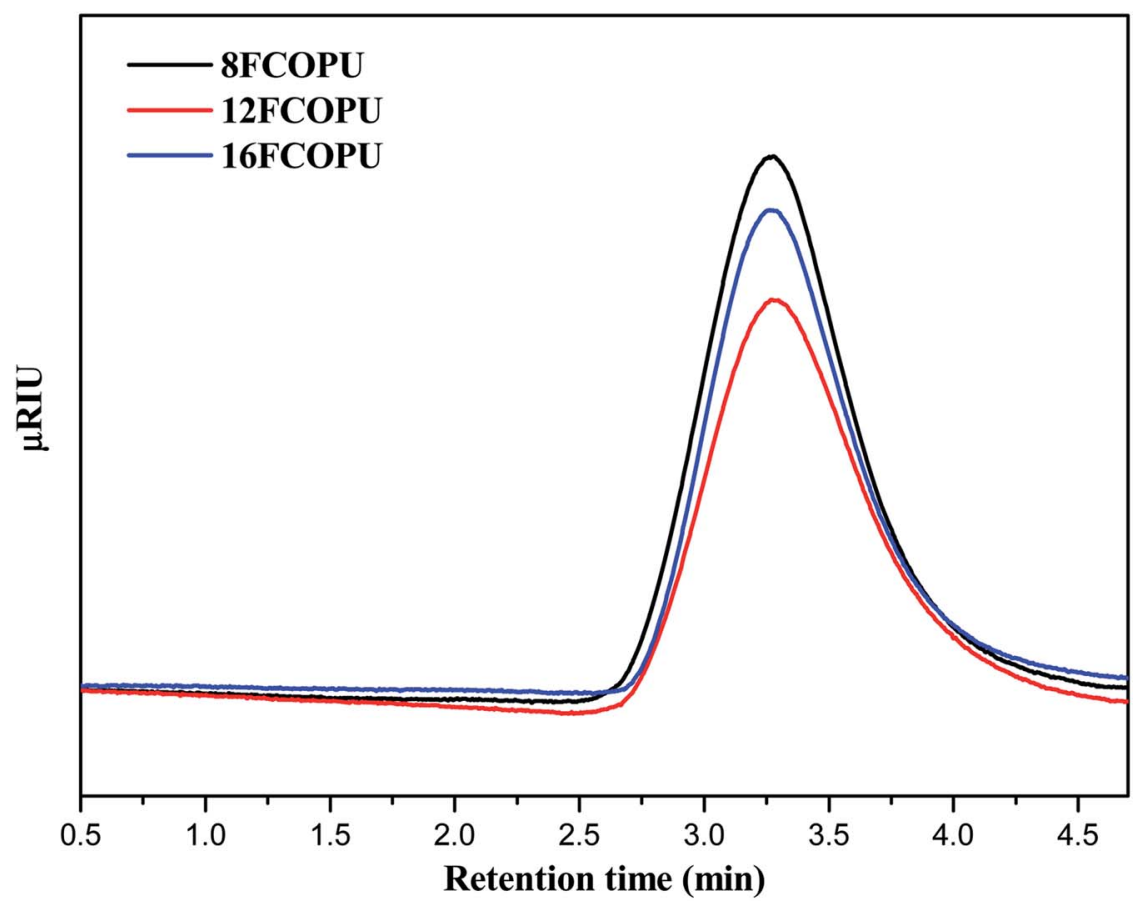

Fig. 1 GPC curves of the FCOPUs.

$-122.79 \mathrm{ppm},-123.90 \mathrm{ppm}$ in the one-dimensional fluorine NMR spectrum; positions of the three peaks were labeled as 13 respectively. To analyze F1-F3 accurately, we analyzed the two strong correlations shown in Fig. 2 (i.e., F1-F2 and F2-F3); previous studies have revealed that ${ }^{4} J(\mathrm{~F}, \mathrm{~F})$ was stronger than ${ }^{3} J(\mathrm{~F}, \mathrm{~F}),{ }^{31}$ meaning that a strong coupling exists in ${ }^{4} J(\mathrm{~F}, \mathrm{~F})$. According to Fig. 2, F-A and $\mathrm{F}-\mathrm{A}^{\prime}$ are most influenced by other elements and are thus labeled as $\mathrm{F} 1$, which shows a ${ }^{4} J(\mathrm{~F}, \mathrm{~F})$ coupling (F1-F2'). Accordingly, $\mathrm{F}-\mathrm{C}$ and $\mathrm{F}-\mathrm{C}^{\prime}$ are labeled as $\mathrm{F} 2$, which shows another ${ }^{4} J(\mathrm{~F}, \mathrm{~F})$ coupling (F2-F3); therefore, F-B and $\mathrm{F}^{-\mathrm{B}^{\prime}}$ are labeled as $\mathrm{F}$. The peak at $-119.81 \mathrm{ppm}(\mathrm{F} 1)$ corresponds to $\mathrm{F}-\mathrm{A}$ and $\mathrm{F}-\mathrm{A}^{\prime}$; the peak at $-122.79 \mathrm{ppm}$ (F2 and $\mathrm{F}^{\prime}$ ) corresponds to $\mathrm{F}-\mathrm{C}$ and $\mathrm{F}-\mathrm{C}^{\prime}$; and the peak at $-123.90 \mathrm{ppm}$ (F3) corresponds to $\mathrm{F}-\mathrm{B}$ and $\mathrm{F}-\mathrm{B}$ '. The relative positions of fluorine were then confirmed. However, the relative positions did not adequately suggest that the fluorinated chain extender was connected to the PUs; thus, a twodimensional NMR spectrum analysis was required to confirm the connection. Fig. 3 presents the ${ }^{1} \mathrm{H}^{19}{ }^{19} \mathrm{~F}$ correlation spectroscopy (COSY) result of the 12FCOPU and shows that the $\mathrm{H}$ atoms of the $\mathrm{CH}_{2}$ group in the fluorinated chain extender exhibits a ${ }^{3} J(\mathrm{H}, \mathrm{F})$ coupling with $\mathrm{F} 1$ at $4.89 \mathrm{ppm}$; the $\mathrm{H}$ atoms also have a weak ${ }^{4} J(\mathrm{~F}, \mathrm{~F})$ coupling with $\mathrm{F} 3$ at $4.88 \mathrm{ppm}$. The NMR of the fluorinated chain extender is shown in Fig. 3. Subsequently, Fig. 4 shows the ${ }^{1} \mathrm{H}^{-13} \mathrm{C}$ HMBC spectrum of the 12FCOPU. A previous study indicated that the position of $\mathrm{O}-\mathrm{C}=\mathrm{O}$ in $\mathrm{PU}$ was at approximately $153 \mathrm{ppm} .{ }^{32}$ With the position of $\mathrm{C}=\mathrm{O}$ corresponding to the position of $\mathrm{H}$ atoms in $\mathrm{CH}_{2}$ at $4.88 \mathrm{ppm}$, the fluorinated chain extender successfully reacted with MDI to form urethane groups.

\subsection{Fourier transform infrared spectroscopy (FTIR)}

Fig. 5(a) illustrates the FTIR spectrum of FCOPUs in a wavenumber range of $4000-650 \mathrm{~cm}^{-1}$; the spectrum reveals five main functional peaks of PU in the FCOPUs, namely peaks caused by $-\mathrm{NH}$ stretching vibration at $3329.13 \mathrm{~cm}^{-1}, \mathrm{CH}_{2}$ stretching vibration at $2927.94 \mathrm{~cm}^{-1}$ and $2858.50 \mathrm{~cm}^{-1}, \mathrm{C}=\mathrm{O}$ stretching vibration at approximately $1724.36 \mathrm{~cm}^{-1}$ (amide I band), -NH bending vibration at $1531.47 \mathrm{~cm}^{-1}$ (amide II band), and stretching vibration of $\mathrm{C}-\mathrm{F}$ group at $1217.08 \mathrm{~cm}^{-1}$. A peak caused by $\mathrm{C}-\mathrm{O}$ stretching vibration at $1064.70 \mathrm{~cm}^{-1}$ is also observed. Additionally, the free NCO groups of MDI are not shown in the spectrum in the wavenumber range of 2240$2275 \mathrm{~cm}^{-1}$, indicating that MDI has reacted with the PCL, castor oil, and chain extender completely.

Fig. 5(b) reveals the absorption peaks in the wavenumber of 2000-650 $\mathrm{cm}^{-1}$. A study verified the existence of hydrogen bonding in PUs with a FTIR; the same study revealed three peak values: $\mathrm{C}=\mathrm{O}_{\text {free }}, \mathrm{C}=\mathrm{O}_{\mathrm{HB} \text { disordered, }}$, and $\mathrm{C}=\mathrm{O}_{\mathrm{HB}}$ ordered, with the peak value of $\mathrm{C}=\mathrm{O}_{\mathrm{HB}}$ ordered observed at approximately $1660 \mathrm{~cm}^{-1} \cdot{ }^{33}$ Another study showed two peak values (free radicals and HBs), in the C-F absorption peak of fluorinated PU; ${ }^{34}$

Table 2 GPC result of FCOPUs

\begin{tabular}{lllll}
\hline Sample & $\begin{array}{l}\text { Retention time } \\
\text { of the peak }(\mathrm{min})\end{array}$ & $\overline{M_{\mathrm{n}}}\left(\times 10^{4}\right)$ & $\overline{M_{\mathrm{w}}}\left(\times 10^{4}\right)$ & $\overline{M_{\mathrm{w}}} / \overline{M_{\mathrm{n}}}$ \\
\hline 8FCOPU & 3.28 & 3.10 & 4.92 & 1.59 \\
12FCOPU & 3.27 & 2.78 & 4.56 & 1.64 \\
16FCOPU & 3.26 & 2.86 & 4.55 & 1.59
\end{tabular}




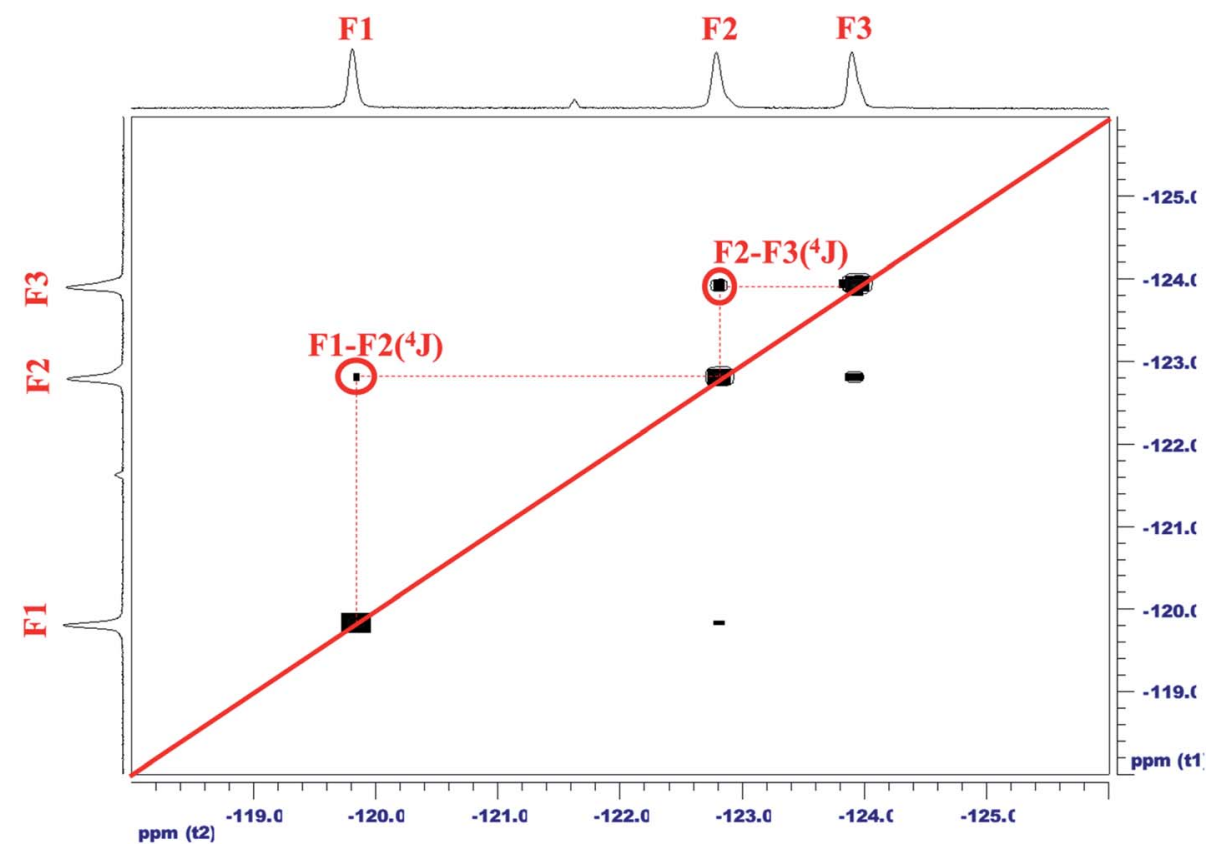

Fig. $2{ }^{19} \mathrm{~F}-{ }^{19} \mathrm{~F}$ COSY NMR spectrum of the 12FCOPU.

the same study calculated the percentage of HBs in fluorinated $\mathrm{PU}$ at $1530 \mathrm{~cm}^{-1}$ because no peaks other than a benzene ring stretching vibration peak were observed at this wavenumber. The following equation can be used to verify the existence of hydrogen in PUs:

$$
\mathrm{A} \%=\frac{I_{\mathrm{H}} / I_{\text {ref }}}{I_{\mathrm{H}} / I_{\text {ref }}+I_{\text {free }} / I_{\text {ref }}}
$$

where $I_{\mathrm{H}}$ is the strength of HBs, $I_{\text {free }}$ refers to the strength of bonds in free radicals, and $I_{\text {ref }}$ denotes the absorption intensity at $1534 \mathrm{~cm}^{-1}$. To explore the influence of the length of fluorinated chain extender on PUs, this study conducted curve fitting at the wavenumber range of $1235-1185 \mathrm{~cm}^{-1}$ (Fig. 6). The curve fitting result uncovered the existence of $\mathrm{C}-\mathrm{O}-\mathrm{C}, \mathrm{C}-\mathrm{F}_{\text {free }}, \mathrm{C}-\mathrm{F}_{\mathrm{HB}}$, and $\mathrm{C}-\mathrm{N}$ absorption peaks in the wavenumber range of 1235$1185 \mathrm{~cm}^{-1}$. After calculation, we discovered that when the

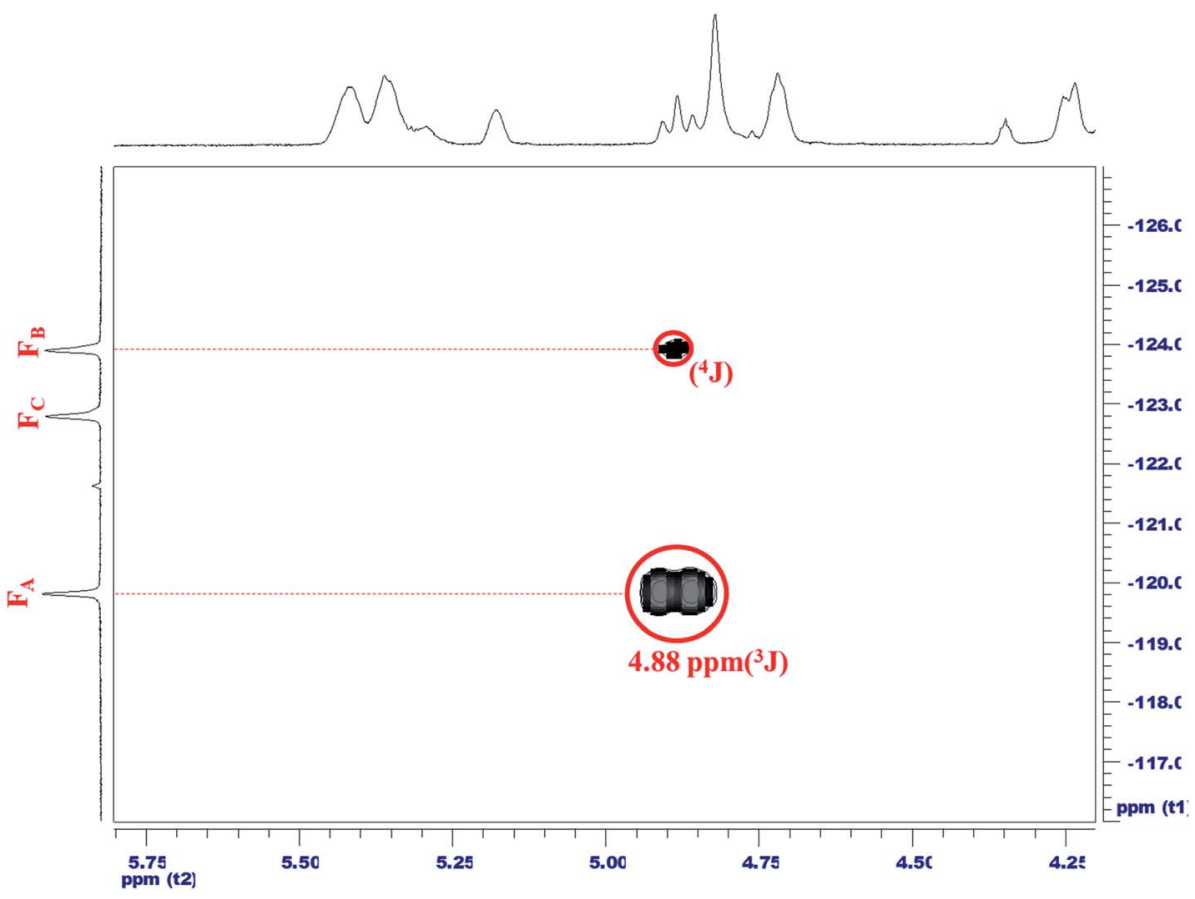

Fig. $3{ }^{1} \mathrm{H}-{ }^{19} \mathrm{~F}$ COSY NMR of $12 \mathrm{FCOPU}$. 


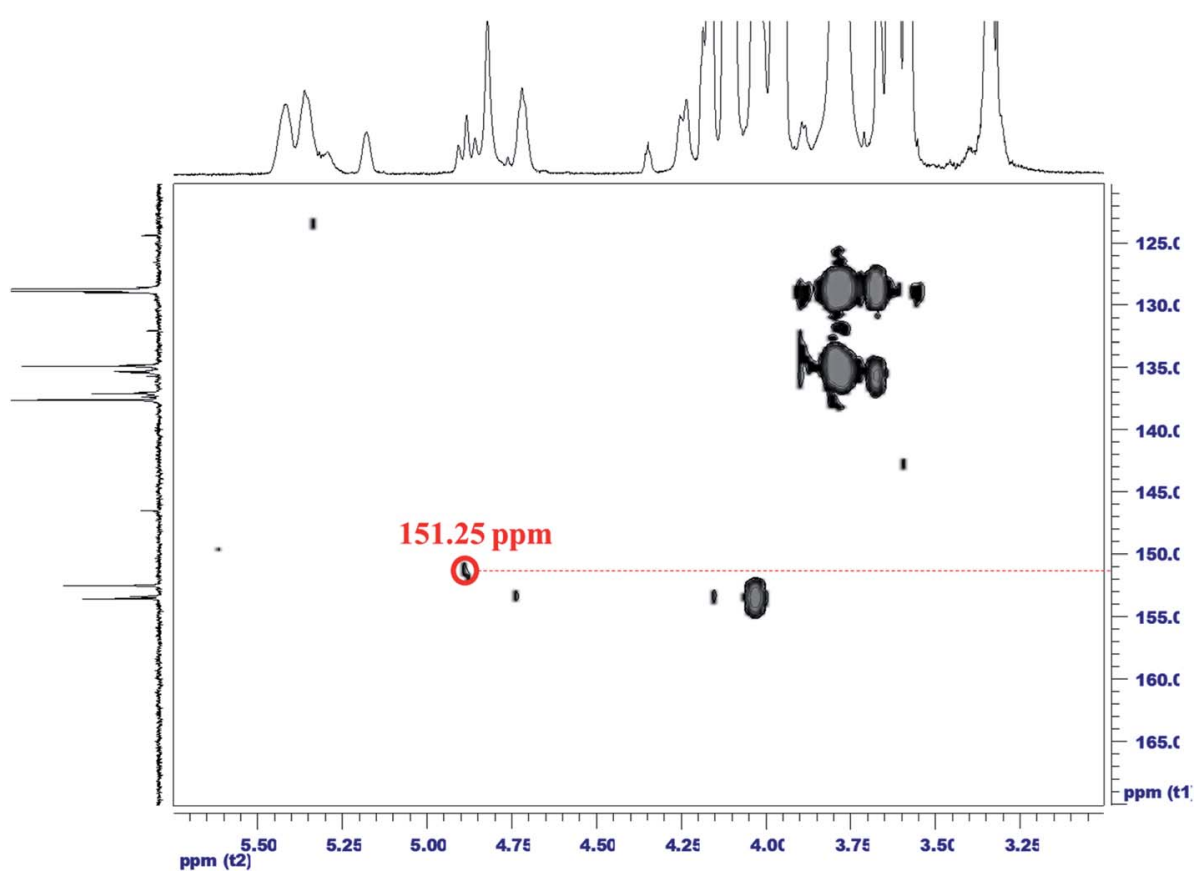

Fig. $4{ }^{1} \mathrm{H}-{ }^{13} \mathrm{C}$ HMBC NMR of 12FCOPU.

length of the FCOPU was extended from 8 FCOPU to $12 \mathrm{FCOPU}$ by using the fluorinated chain extender, the ratio of $\mathrm{C}-\mathrm{F}_{\mathrm{HB}}$ to $\mathrm{C}-$ $\mathrm{F}_{\text {free }}$ increased from $47.08 \%$ to $88.07 \%$; when the length was further extended, such a ratio slightly increased to $93.28 \%$. Accordingly, a longer chain length is more conducive to enhancing hydrogen bonding in FCOPUs.

\subsection{X-ray photoelectron spectroscopy (XPS)}

Fig. 7 illustrates the elements and their bonding states in FCOPUs; each of the spectra contains four major peaks, C 1s, O $1 \mathrm{~s}, \mathrm{~N} 1 \mathrm{~s}$, and $\mathrm{F} 1 \mathrm{~s}$ and the catalyst, Sn $3 \mathrm{~d}$. Table 3 lists our calculated content and the binding energies of elements and shows that the content of fluorine increased from $0.41 \%$ to $1.03 \%$ with increases in the chain extender's length. A study suggested that in solid PU films, high fluorine content in the PU is relatively conducive to moving fluorinated segments to the surface of the thin film..$^{35}$ According to the XPS of the FCOPUs, the fluorine content in the surface of $16 \mathrm{FCOPU}$ was $1.03 \%$, despite the theoretical fluorine content being $1.92 \%$; this may have resulted from castor oil with trifunctional groups, which may have formed the crosslinked structure of the FCOPUs, and such a crosslinked structure may inhibit fluorinated segments from moving outward to the film surface. ${ }^{36}$ Additionally, the results revealed the $\mathrm{O} 1 \mathrm{~s}$ binding energies of $8 \mathrm{FCOPU}$, $12 \mathrm{FCOPU}$, and 16FCOPU to be $532.38,532.17$, and $531.87 \mathrm{eV}$, respectively, implying that the $\mathrm{O} 1 \mathrm{~s}$ binding energies decreased slightly with increases in the chain length. Berger et al. ${ }^{37}$ discussed the interaction of fluorine and revealed the dipoledipole interaction in $\mathrm{C}-\mathrm{F} \cdots \mathrm{C}=\mathrm{O}$, indicating that increases in the length of a fluorinated chain extender might change the molecular interactions in PU films. Therefore, we performed curve fitting on $\mathrm{C} 1 \mathrm{~s}$ of the FCOPUs to discuss molecular interactions (Fig. 8). The $\mathrm{C}$ 1s curve of the FCOPUs reveals binding energies as follows: $\mathrm{C}=\mathrm{C}(283.7 \mathrm{eV}), \mathrm{C}-\mathrm{C}(284.8 \mathrm{eV})$, $\mathrm{C}-\mathrm{N}(285.2 \mathrm{eV}), \mathrm{C}-\mathrm{O}(285.7 \mathrm{eV}), \mathrm{C}-\mathrm{O}-\mathrm{C}(287.0 \mathrm{eV}), \mathrm{O}-\mathrm{C}=\mathrm{O}$ $(289.5 \mathrm{eV})$, and $\mathrm{C}-\mathrm{F}_{2}(292 \mathrm{eV})$, these peak positions are consistent with these report. ${ }^{38-40}$ The results indicated that with an increased length of fluorinated chain extender, the $\mathrm{C}^{-\mathrm{F}_{2}}$ binding energy increased from 291.81 to $292.15 \mathrm{eV}$, and such an increase of energy was contributed by the hydrogen bonding in $\mathrm{C}-\mathrm{F} \cdots \mathrm{H}-\mathrm{N}$. Specifically, a longer length of perfluorinated alkyl chains indicated higher content of fluorine in the PUs, thus increasing the number of hydrogen bonding interactions in C$\mathrm{F} \cdots \mathrm{H}-\mathrm{N}$; this result was consistent with that of the FTIR. The $\mathrm{O}-\mathrm{C}=\mathrm{O}$ binding energy decreased slightly from 289.69 to $289.54 \mathrm{eV}$; such a decrease might be caused by the steric hindrance increasing with the increasing length of the fluorinated chain extender, which disrupted hydrogen bonding in $\mathrm{C}=\mathrm{O} \cdots \mathrm{N}-\mathrm{H}$, as well as by a dipole-dipole interaction existing in $\mathrm{C}-\mathrm{F} \cdots \mathrm{C}=\mathrm{O}^{30,41}$

\subsection{Surface roughness analysis}

Fig. 9 presents the topography (left) and phase data (right) of 8FCOPU, 12FCOPU, and 16FCOPU. The topography revealed continuous protrusions in FCOPUs. We then calculated the average surface roughness values of 8FCOPU $(2.59 \mathrm{~nm})$, 12FCOPU $(3.79 \mathrm{~nm})$, and 16FCOPU $(4.81 \mathrm{~nm})$, which suggested FCOPUs with long fluorinated chain extenders exhibited rough surfaces and numerous continuous protrusions on the surface. Namely, 16FCOPU had the roughest surface of all the FCOPU samples. The phase data indicated that 8FCOPU exhibited microphase mixing; when the chain length was increased (12FCOPU), microphase separation was observed, and the microphase separation became more distinct when the chain 
(a)

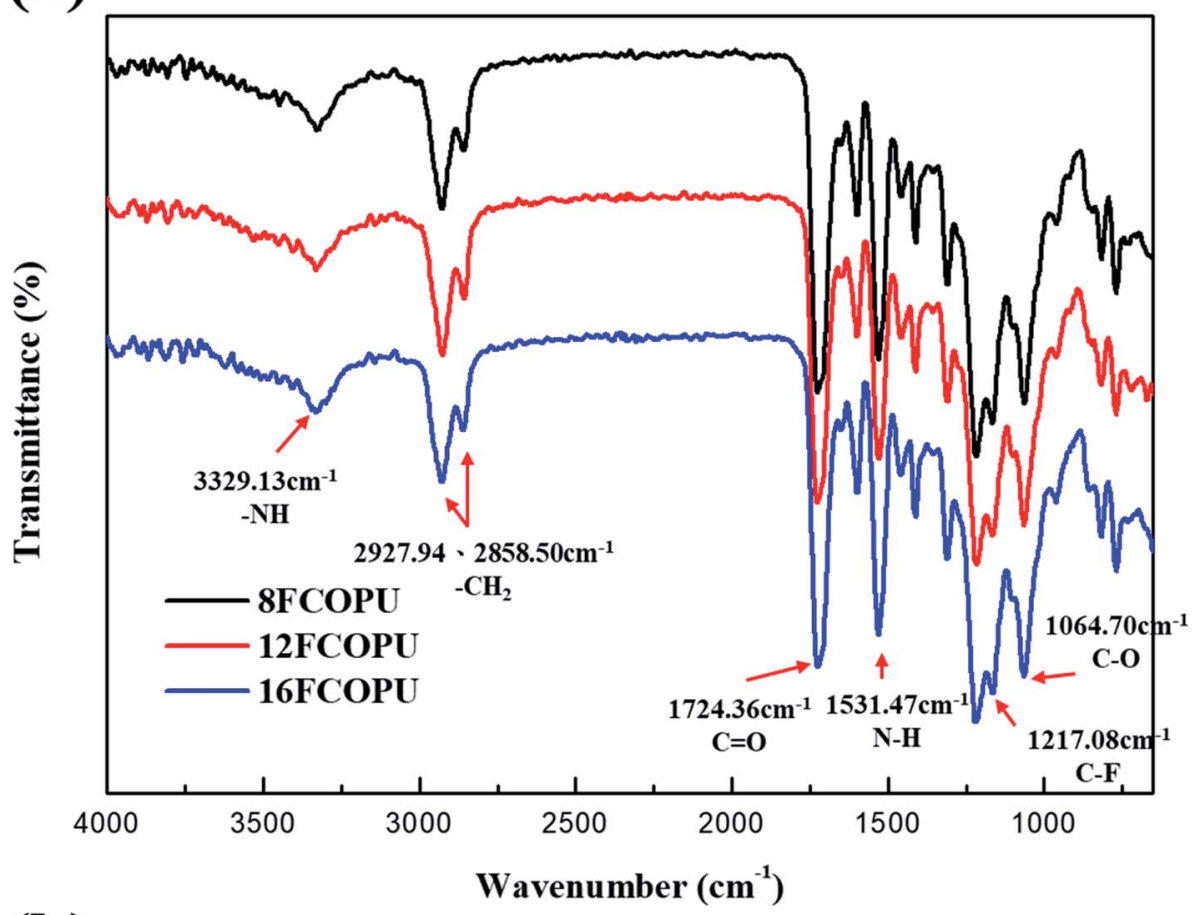

(b)

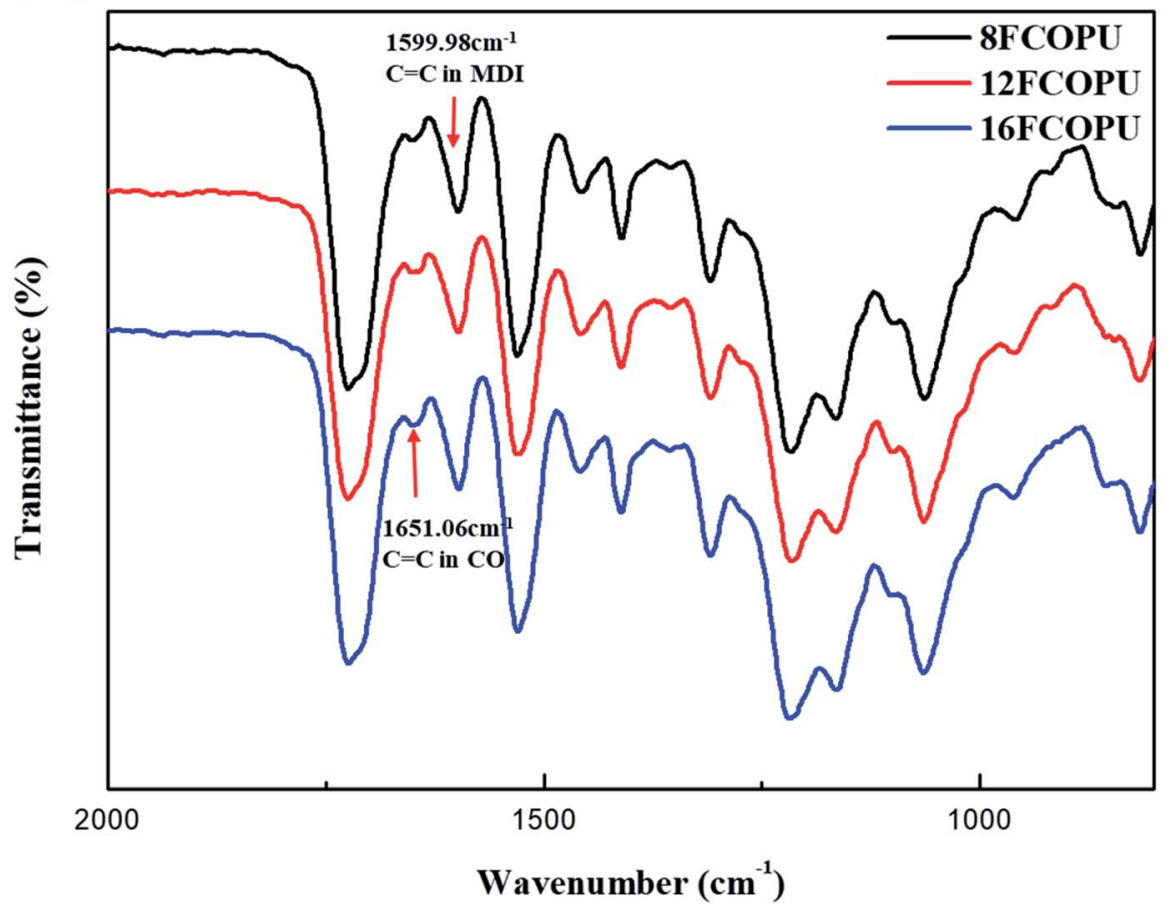

Fig. 5 FT-IR spectra of the FCOPUs at the wavenumber range of (a) $4000-650 \mathrm{~cm}^{-1}$; (b) $2000-800 \mathrm{~cm}^{-1}$.

length was further increased (16FCOPU). Specifically, FCOPUs synthesized with longer fluorinated chain extenders exhibited more distinct microphase separation because longer fluorinated chain extenders contained more fluorine. Additionally, the fluorinated chain extender and MDI were used as the hard segments in the FCOPUs, $\mathrm{C}-\mathrm{F}$ and $\mathrm{C}=\mathrm{O}$ exhibited interactions, and $\mathrm{HBs}$ existed between $\mathrm{C}-\mathrm{F}$ and $\mathrm{N}-\mathrm{H}$; therefore, fluorine in FCOPUs enhanced the interactions between hard segments and thus led to microphase separation. Furthermore, the increased interactions in the polymer resulted in unstable film formation process of FCOPUs, thus leading to increased surface roughness. 
(a)

(b)

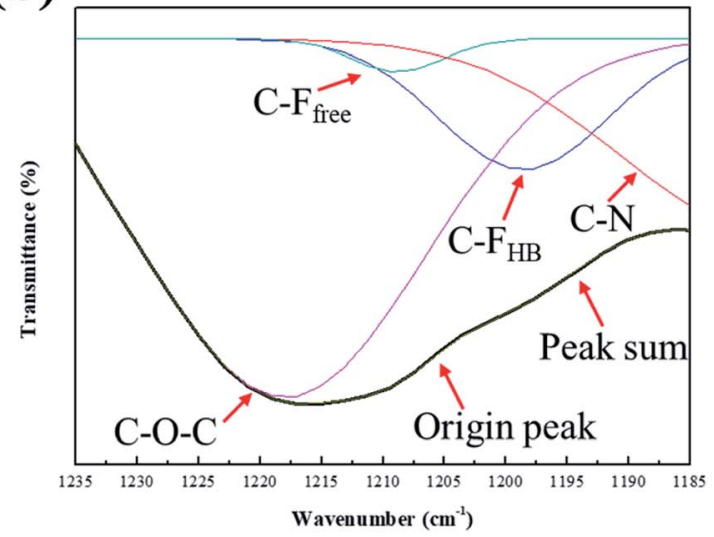

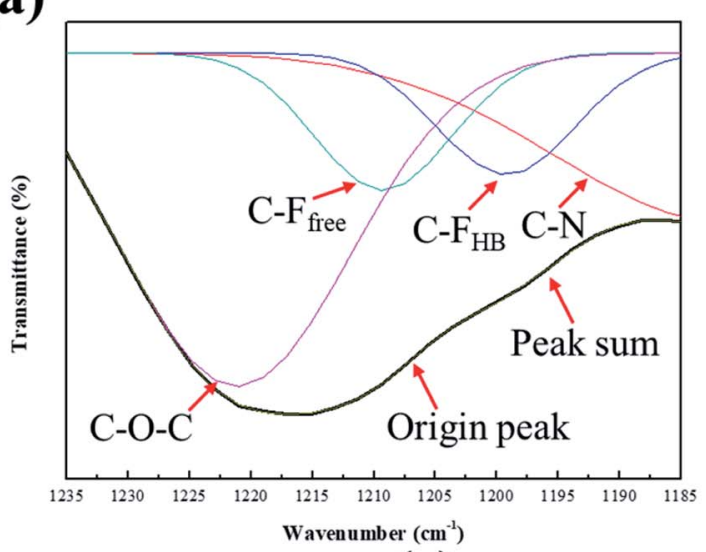

(c)

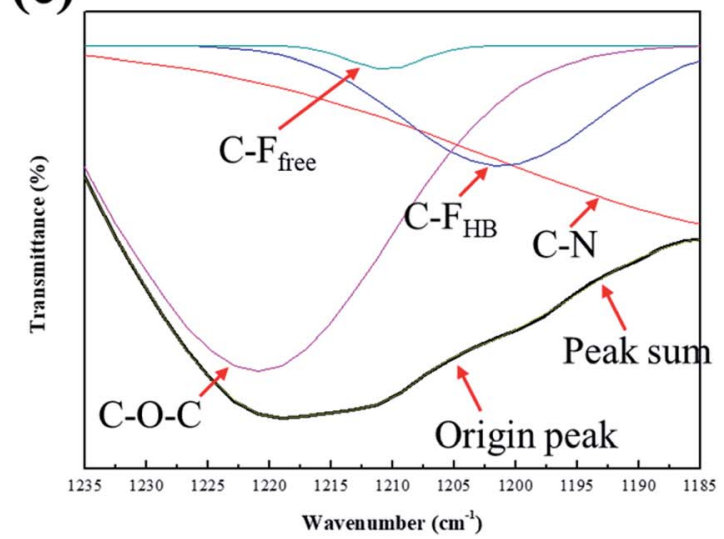

Fig. 6 FT-IR spectra of (a) 8FCOPU; (b) 12FCOPU; (c) 16FCOPU at the wavenumber range of $1235-1185 \mathrm{~cm}^{-1}$.

\subsection{Thermal properties}

Fig. 10 depicts the TGA curve of the FCOPUs synthesized using fluorinated chain extenders with different lengths. Table 4 presents the onset decomposition temperatures $\left(T_{\text {onset }}\right)$ and calculated residual weight at $700^{\circ} \mathrm{C}$ and shows the $T_{\text {onset }}$ results of $8 \mathrm{FCOPU}\left(319.63^{\circ} \mathrm{C}\right), 12 \mathrm{FCOPU}\left(321.77^{\circ} \mathrm{C}\right)$, and $16 \mathrm{FCOPU}(324.80$

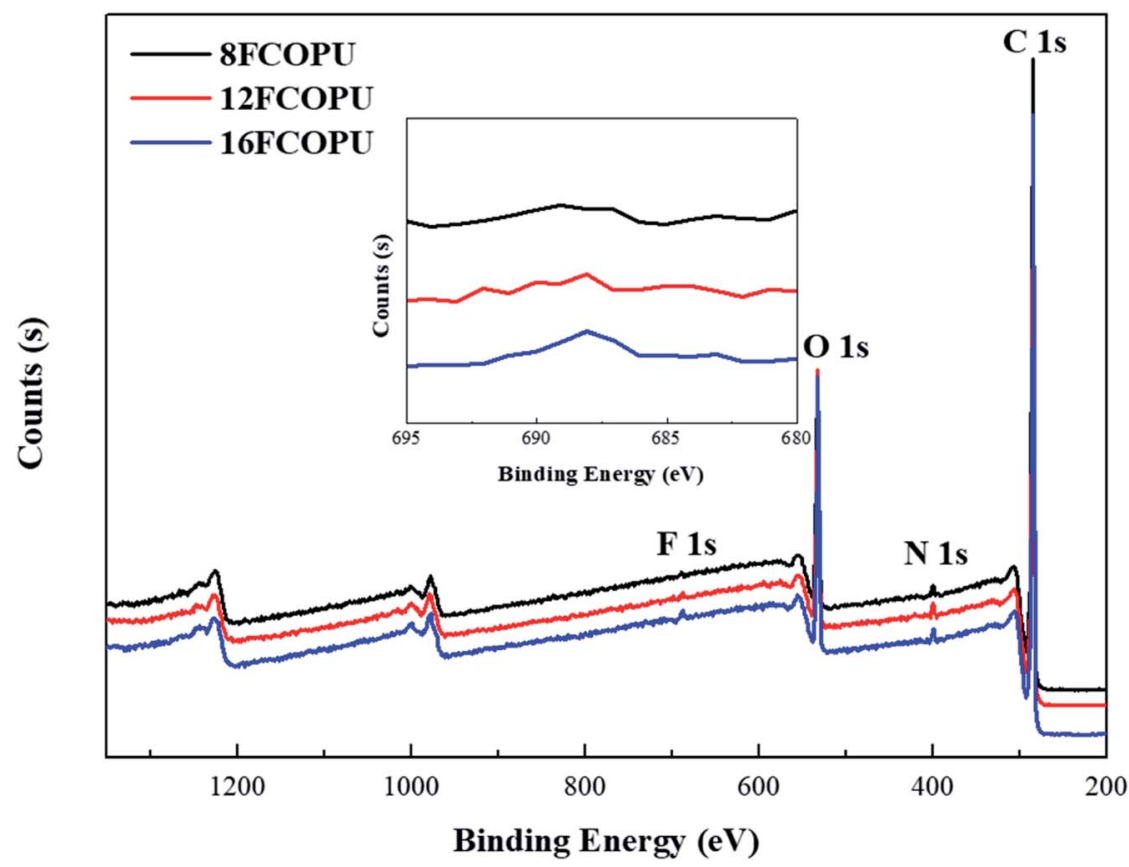

Fig. 7 XPS survey spectra of the FCOPUs. 
Table 3 XPS peak characteristics of the FCOPUs

\begin{tabular}{lllc}
\hline Sample name & Content & Binding energy (eV) & Atomic ratio (\%) \\
\hline \multirow{2}{*}{ 8FCOPU } & C 1s & 284.96 & 82.14 \\
& O 1s & 532.38 & 15.82 \\
& N 1s & 399.94 & 1.60 \\
& F 1s & 687.96 & 0.41 \\
12FCOPU & Sn 3d & 491.64 & 0.04 \\
& C 1s & 284.60 & 81.22 \\
& O 1s & 532.17 & 17.55 \\
& N 1s & 399.93 & 0.74 \\
16FCOPU & F 1s & 688.8 & 0.45 \\
& Sn 3d & 486.97 & 0.04 \\
& C 1s & 284.24 & 79.6 \\
& O 1s & 531.87 & 17.43 \\
& N 1s & 399.52 & 1.89 \\
& F 1s & 688.05 & 1.03 \\
& Sn 3d & 494.68 & 0.05
\end{tabular}

$\left.{ }^{\circ} \mathrm{C}\right)$. These results indicated that increased length of $\mathrm{CF}_{2}$ in fluorinated PUs increased the temperature of initial decomposition, which might be attributed to the strong bonding energy of $-\mathrm{CF}_{2}$; moreover, the covalent radius of a fluorine atom is half of the $\mathrm{C}-\mathrm{C}$ bond length, thus being able to shield the $\mathrm{C}-\mathrm{C}$ backbone and ensuring the stability of the $\mathrm{C}-\mathrm{C}$ bond. The result also showed that an increased chain extender length was associated with an increased residual weight at $700{ }^{\circ} \mathrm{C}$; specifically, the residual weight of the FCOPU at $700{ }^{\circ} \mathrm{C}$ increased from $4.17 \%$ (8FCOPU) to $6.78 \%$ (16FCOPU). This result might be caused by the increased number of carbon atoms in the polymer in the process of chain extension, which increased the residual weight at $700{ }^{\circ} \mathrm{C}$.

Fig. 11 presents the DSC curve of the FCOPU; Table 4 compiles the $T_{\mathrm{g}}$ and melting temperature $\left(T_{\mathrm{m}}\right.$.). The results revealed the $T_{\mathrm{g}}$ of 8 FCOPU $\left(-1.66{ }^{\circ} \mathrm{C}\right), 12 \mathrm{FCOPU}\left(0.63{ }^{\circ} \mathrm{C}\right)$, and 16FCOPU $\left(3.45^{\circ} \mathrm{C}\right)$ and the $T_{\mathrm{m}}$ of $8 \mathrm{FCOPU}\left(131.09{ }^{\circ} \mathrm{C}\right), 12 \mathrm{FCOPU}\left(135.77^{\circ} \mathrm{C}\right)$, and 16FCOPU $\left(145.13{ }^{\circ} \mathrm{C}\right)$, implying that an increased fluorinated chain extender length was associated with increased $T_{\mathrm{g}}$ and $T_{\mathrm{m}}$. Such increases might be attributed to a long fluorinated chain extender with numerous $\mathrm{CF}_{2}$ groups, which increased interactions in the fluorinated PU, including van der Waals interactions in C$\mathrm{F} \cdots \mathrm{H}-\mathrm{N}$ and $\mathrm{C}-\mathrm{F} \cdots \mathrm{C}=\mathrm{O}$. Therefore, the increased degree of physical crosslinking in the polymer chains required increased thermal energy for polymer chain movement, thereby increasing the $T_{\mathrm{g}}$ and $T_{\mathrm{m}}$. This result was consistent with the XPS and FTIR results; furthermore, the TGA and DSC suggested that increased length of a fluorinated chain extender was conducive to enhancing the thermal stability of fluorinated PUs.

\subsection{Dynamic mechanical analysis (DMA)}

Fig. 12 presents the tan $\delta$ of FCOPUs synthesized using fluorinated chain extenders with different lengths. Dynamic glass transition temperature $\left(T_{\mathrm{gd}}\right)$ is defined as the dynamic glass
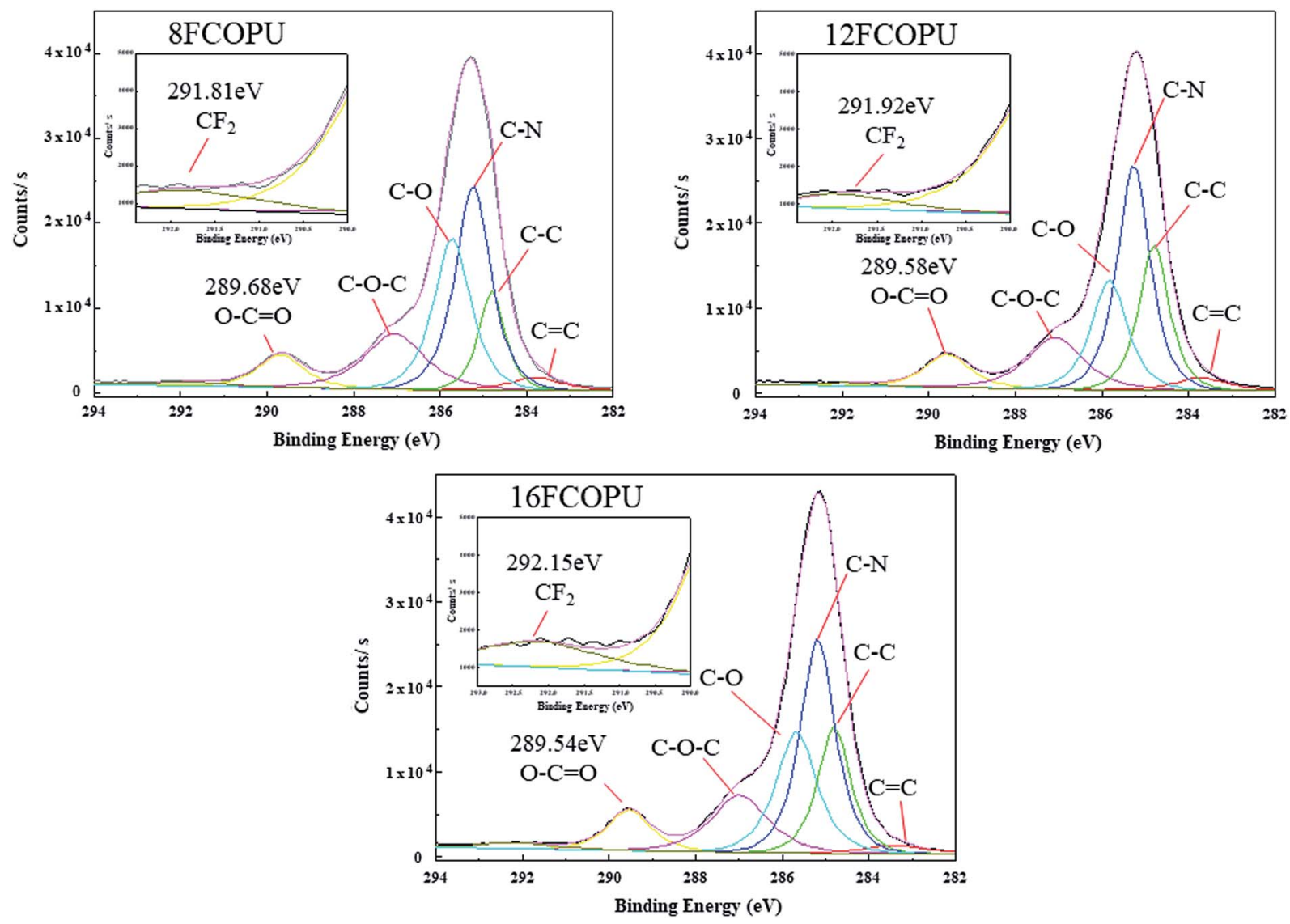

Fig. 8 C 1s fit theory of FCOPUs. 


\section{Morphology}

\section{FCOPU}

\section{FCOPU}

\section{FCOPU}
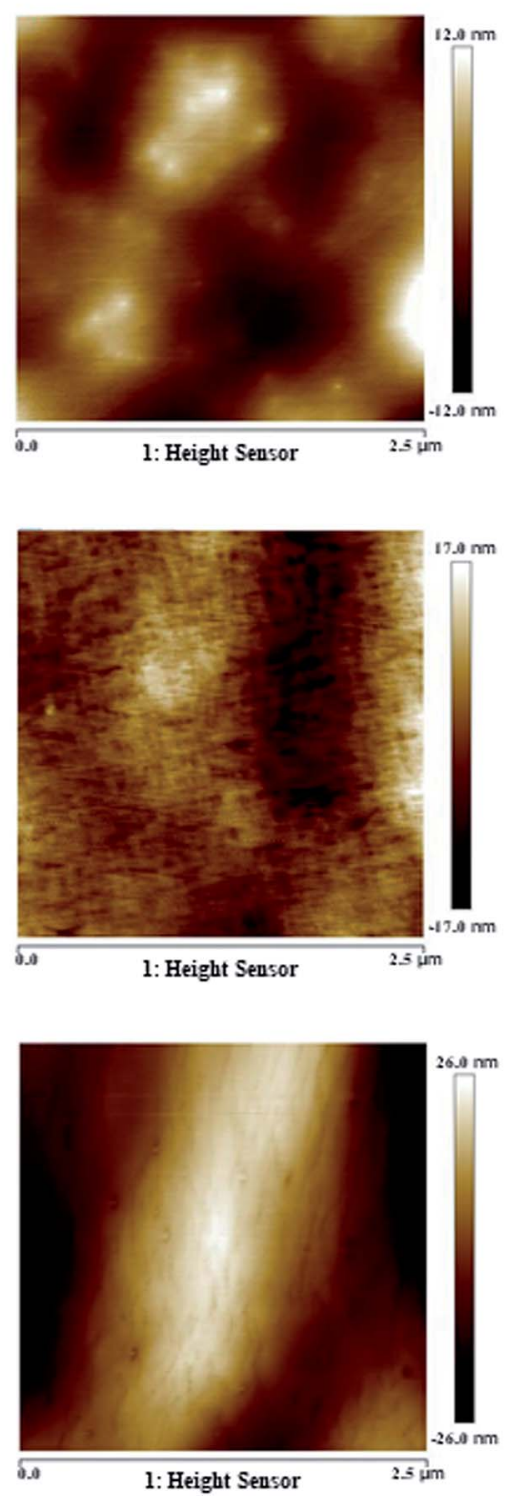

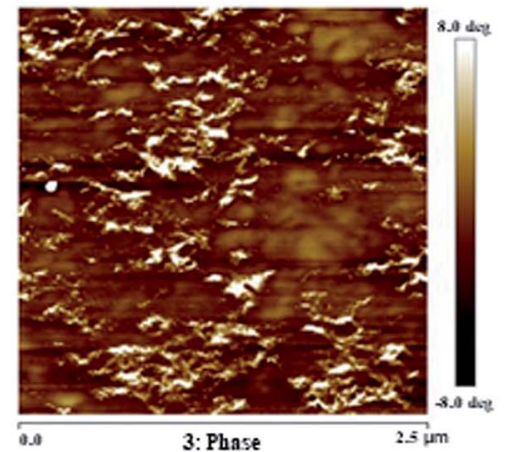

Phase
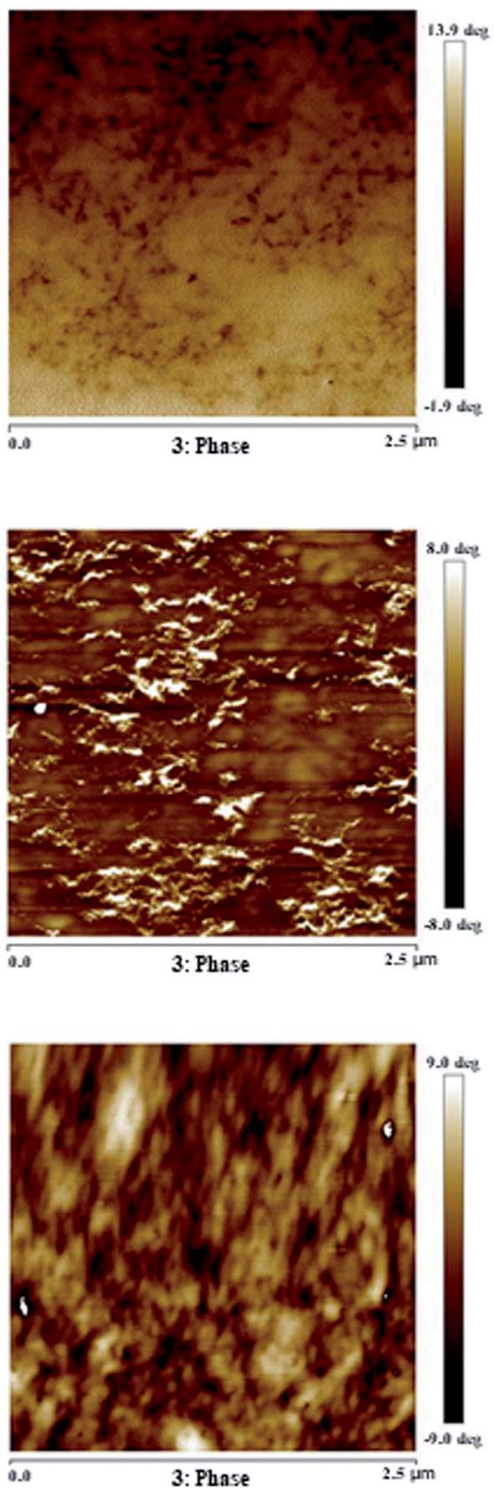

Fig. 9 AFM topographic and phase images of the FCOPUs.

transition temperature of FCOPUs. Table 5 compiles the maximum values of $T_{\mathrm{gd}}$ and $\tan \delta$; the maximum $T_{\mathrm{gd}}$ values are as follows: $8 \mathrm{FCOPU}\left(1.88^{\circ} \mathrm{C}\right), 12 \mathrm{FCOPU}\left(3.24^{\circ} \mathrm{C}\right)$, and $16 \mathrm{FCOPU}$ $\left(6.74{ }^{\circ} \mathrm{C}\right)$. The result indicated that the dynamic glass transition temperature increased with increases in the length of the fluorinated chain extender. Possibly a long fluorinated chain extender contains numerous fluorine atoms, thereby increasing the interactions in FCOPUs, increasing the thermal energy required by polymer chain movement, and improving the thermal stability of the FCOPUs. The result was consistent with that suggested by the TGA and DSC. The maximum values of $\tan \delta$ of FCOPUs were shown to decrease from 0.6503 to 0.5907 with the increased length of the fluorinated chain extender. Possibly numerous fluorine atoms contained in the FCOPUs led to an increased number of physical crosslinks $(\mathrm{C}-\mathrm{F} \cdots \mathrm{C}=\mathrm{O}$ and $\mathrm{C}-\mathrm{F} \cdots \mathrm{H}-\mathrm{N}$ ), which in turn resulted in reduced mobility of polymer chains in the FCOPUs. In other words, $\tan \delta$ is obtained by dividing $E^{\prime \prime}$ by $E^{\prime}$, and therefore the more fluorine is in the FCOPUs, the lower the viscosity is, and the higher the elasticity is. Furthermore, Table 5 reveals the crosslink density of 8FCOPU (0.02249 $\left.\mathrm{mol} \mathrm{cm}{ }^{-3}\right), 12$ FCOPU (0.02373 $\left.\mathrm{mol} \mathrm{cm}^{-3}\right)$,

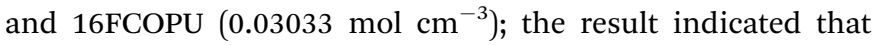
FCOPUs synthesized by a longer fluorinated chain was associated with an increased crosslink density. This study employed the swelling method and used the Flory-Rehner equation to calculate the crosslink density of FCOPUs. A previous study indicated that crosslink density calculated using the swelling method was the sum of chemical and physical crosslinks. ${ }^{42}$ 


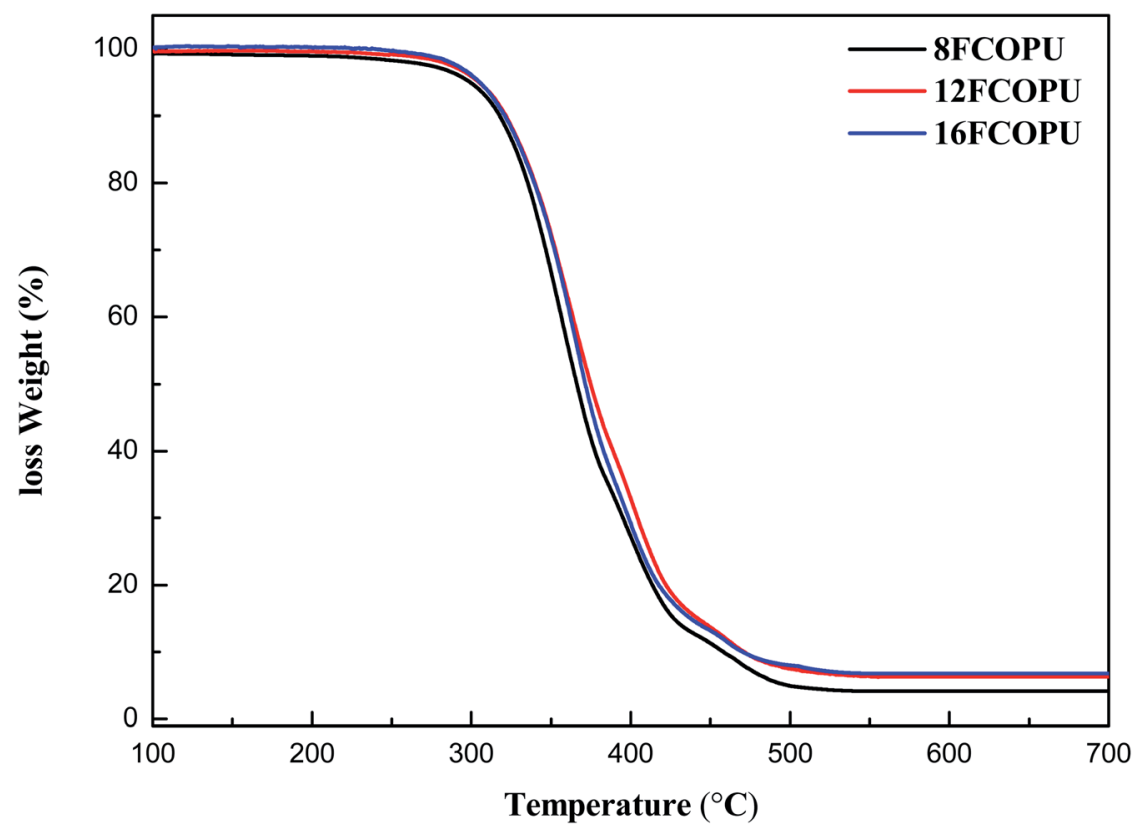

Fig. 10 TGA curves of the FCOPUs.

Table 4 Thermal properties of the FCOPUs

\begin{tabular}{llllll}
\hline & \multicolumn{1}{l}{ TGA } & & DSC \\
\cline { 2 - 3 } \cline { 5 - 6 } Designation & $T_{\text {onset }}\left({ }^{\circ} \mathrm{C}\right)$ & $\begin{array}{l}700{ }^{\circ} \mathrm{C} \\
\text { residue }\end{array}$ & & $T_{\mathrm{g}}\left({ }^{\circ} \mathrm{C}\right)$ & $T_{\mathrm{m}}\left({ }^{\circ} \mathrm{C}\right)$ \\
\hline 8FCOPU & 319.6 & $4.2 \%$ & & -1.7 & 131.1 \\
12FCOPU & 321.8 & $6.3 \%$ & & 0.6 & 135.8 \\
16FCOPU & 324.8 & $6.8 \%$ & & 3.5 & 145.1
\end{tabular}

Accordingly, because the FCOPUs prepared by the present study all had the same number of chemical crosslinks, we verified that FCOPUs synthesized using long fluorinated chains increased the degree of physical crosslinking and improved the mechanical properties of FCOPUs.

\subsection{Tensile properties}

Fig. 13 depicts the stress-strain curve of the FCOPUs synthesized using the fluorinated chain extenders with different lengths; the maximum tensile strength, fracture strain, and

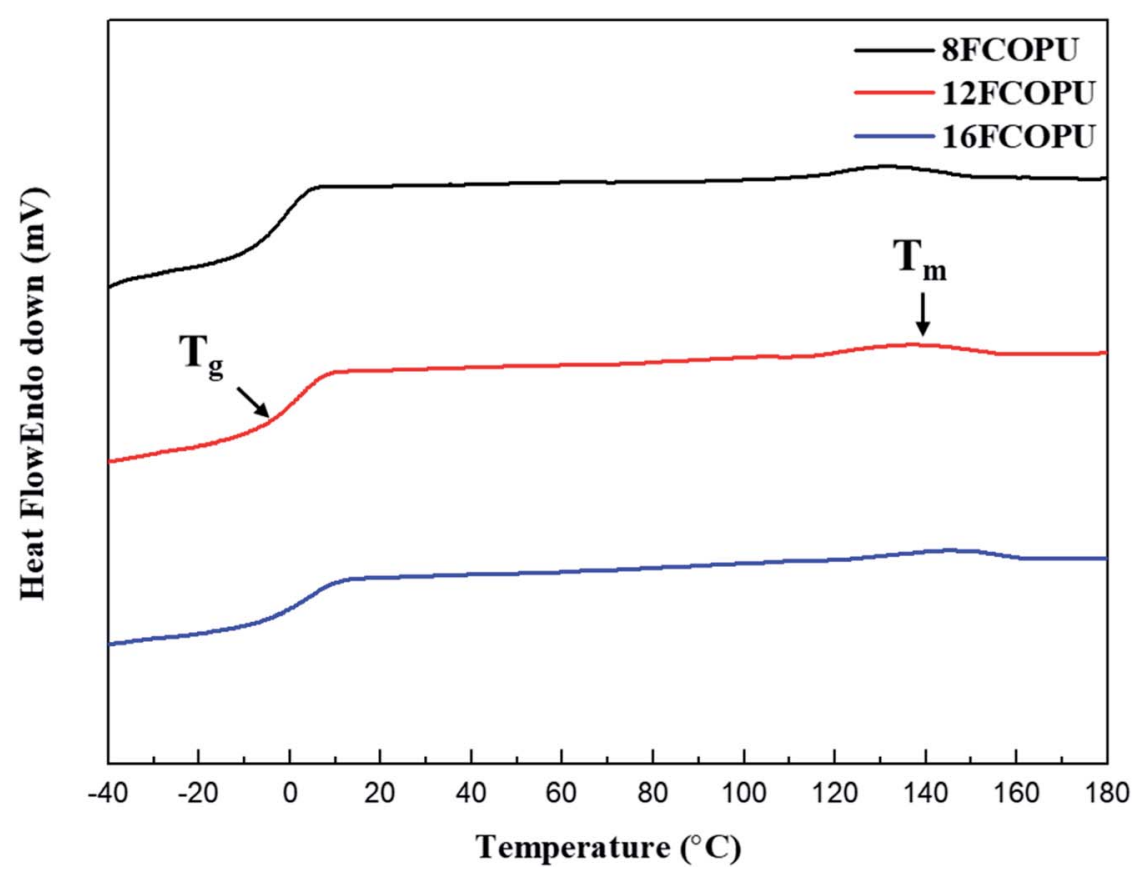

Fig. 11 DSC thermograms of the FCOPUs. 


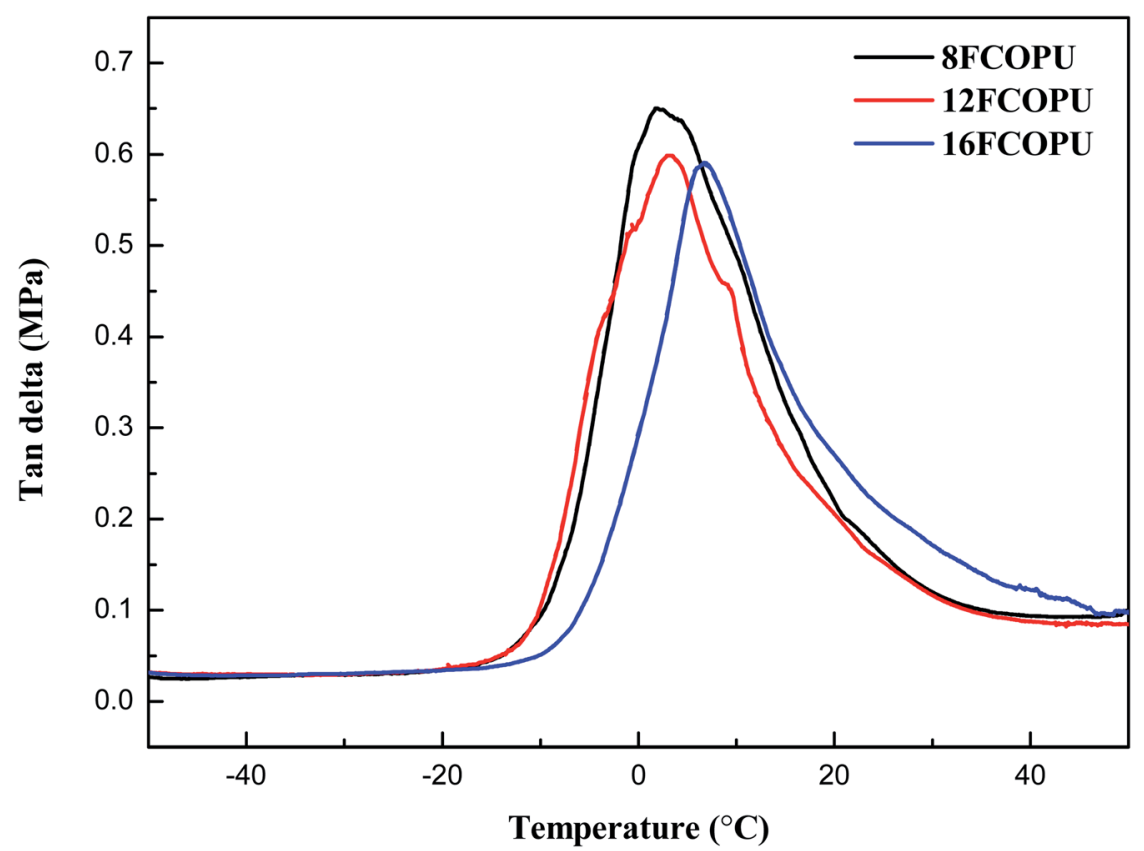

Fig. 12 DMA $\tan \delta$ curves of the FCOPUs.

Young's modulus are compiled in Table 6. The results (maximum tensile strength/elongation at break) are shown as follows: 8FCOPU (17.967 MPa/779.67\%), 12FCOPU (19.226 $\mathrm{MPa} / 775.73 \%)$, and 16FCOPU (20.835 MPa/768.2\%). According to these figures, the tensile strength of FCOPUs increased with increases in the length of the fluorinated chain extender, which may because an increased number of van der Waals interactions in $\mathrm{C}-\mathrm{F} \cdots \mathrm{C}=\mathrm{O}$ and $\mathrm{C}-\mathrm{F} \cdots \mathrm{H}-\mathrm{N}$ produced more physical crosslinks in 18FCOPUs, thereby inhibiting the mobility of polymer chain and maximizing the tensile strength. The Young's moduli of 8FCOPU (0.222 MPa), 12FCOPU (0.243 MPa), and 16FCOPU (0.26 MPa) showed that the longer the fluorinated chain extender used for FCOPU synthesis was, the higher the stiffness of the chain extender was. Specifically, an increased content of fluorine in FCOPUs was associated with increased interactions in FCOPUs; accordingly, the 16FCOPU, compared with the other samples, showed the highest resistance to polymer chain breakage by external force. These mechanical analysis results were consistent with the DMA results.

\subsection{Hydrolytic degradation}

To develop durable degradable materials, this study tested the degradability of FCOPUs and COPU without fluorinated segments in a $3 \mathrm{wt} \% \mathrm{NaOH}$ solution and recorded the weight losses in Fig. 14. The result suggested that after 18 days of hydrolysis in a $3 \mathrm{wt} \% \mathrm{NaOH}$ solution, the weight loss of the 16 FCOPU (22.28\%) was lower than that of the COPU $(28.88 \%)$. This result was due to the physical crosslinking effect of hard segments, which served as the physical crosslinks in PUs and thus improved the mechanical strength and the physical properties, namely hardness and solvent resistance, of PUs. ${ }^{43}$ The degradability of PUs was attributed mainly to the $\mathrm{O}-\mathrm{C}=\mathrm{O}$ groups in castor oil and PCL molecules. ${ }^{44}$ When FCOPUs were dipped in a $\mathrm{NaOH}$ solution, $\mathrm{OH}^{-}$attacked $\mathrm{O}-\mathrm{C}=\mathrm{O}^{*}$ to break the double bonds and attached itself to $\mathrm{O}^{-} \mathrm{C}^{*}-\mathrm{O}^{-}$; subsequently, $\mathrm{O}^{-}$ attacked $\mathrm{O}^{*}-\mathrm{C}(\mathrm{OH})-\mathrm{O}^{-}$, detached the bonds, added electrons to $\mathrm{O}^{-}$, and formed the following degraded form: $-\mathrm{OH}+\mathrm{HO}-\mathrm{C}=\mathrm{O}$. In an alkaline solution, $-\mathrm{COOH}$ and $-\mathrm{OH}$ are dehydrogenated to $-\mathrm{O}^{-}$and $-\mathrm{COO}^{-}$; the ionic bonds between the negative electrons and $\mathrm{Na}^{+}$form -ONa and -COONa, which can be reduced by $\mathrm{H}_{2} \mathrm{O}$ to $-\mathrm{OH}$ and $-\mathrm{COOH}$. In this study, the PCL segments were degraded to 6-hydroxyhexanoic acid and diethylene glycol; the castor oil segments were degraded to glycerol (Fig. 15). With this process repeating continuously, the FCOPU film was degraded in the alkaline solution and started losing weight. This, together with the other analysis results, indicated that high fluorine content in PUs produced numerous physical crosslinks in FCOPUs, which increased the durability of FCOPUs in alkaline solutions.

\subsection{SEM morphology analysis}

Fig. 16 presents the FCOPU and COPU surface at different times in the degradation process. For an effective investigation on the effect of the fluorinated chain extender length on the degradation properties of FCOPUs, this study posited that the

Table 5 DMA and crosslinking density results of the FCOPUs

\begin{tabular}{llll}
\hline Sample & $\begin{array}{l}T_{\text {gd }} \text { from } \\
\tan \delta\left({ }^{\circ} \mathrm{C}\right)\end{array}$ & Tan $\delta_{\max }$ & $\begin{array}{l}\text { Crosslinking } \\
\text { density }\left(\mathrm{mol} \mathrm{cm}^{-3}\right)\end{array}$ \\
\hline 8FCOPU & 1.9 & 0.650 & 0.02249 \\
12FCOPU & 3.2 & 0.599 & 0.02373 \\
16FCOPU & 6.7 & 0.591 & 0.03033
\end{tabular}




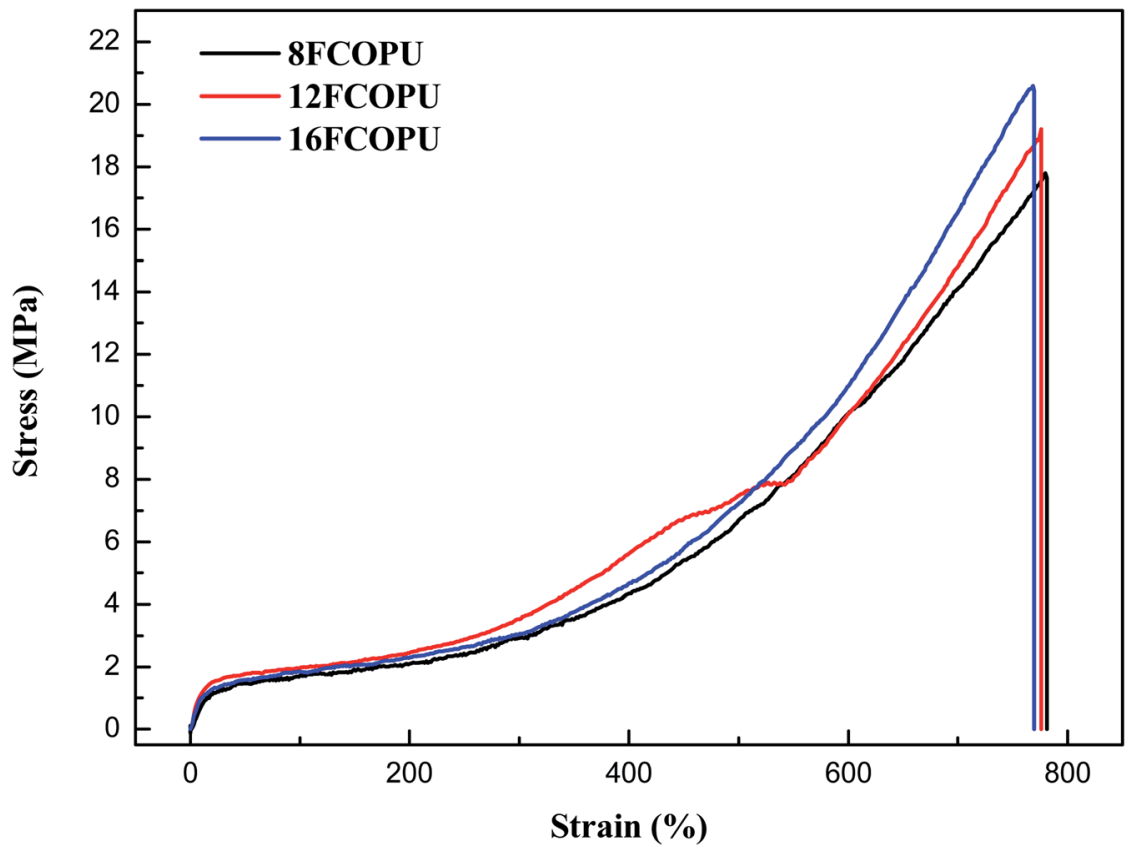

Fig. 13 Tensile properties of the FCOPUs.

Table 6 Tensile properties of the FCOPUs

\begin{tabular}{llll}
\hline Sample & $\begin{array}{l}\text { Tensile strength } \\
(\mathrm{MPa})\end{array}$ & $\begin{array}{l}\text { Young's } \\
\text { modulus (MPa) }\end{array}$ & $\begin{array}{l}\text { Elongation at } \\
\text { break }(\%)\end{array}$ \\
\hline 8FCOPU & 18.0 & 0.22 & 780 \\
12FCOPU & 19.2 & 0.24 & 771 \\
16FCOPU & 20.8 & 0.26 & 768
\end{tabular}

equivalence of degradable monomers (castor oil and PCL) was identical in all FCOPU samples. The result showed that the surface of COPU still exhibited larger and growing pores, all samples with fluorinated segments showed only minor pores on the surface on the sixth day of degradation. On the 12th day of degradation, FCOPU, 8FCOPU and 12FCOPU exhibited noticeable pores on their surface. On the 18th day of degradation, the pores grew larger. Compared with other samples, after degradation, the surface of COPU still exhibited larger and growing pores, and the 16FCOPU exhibited much smaller pores on its surface on the 6th, 12th, and 18th day of degradation; this might because FCOPUs with a longer fluorinated chain extender contained more physical crosslinks, which created difficulties for alkaline water molecules to diffuse to hydrophobic hard segments or be retained in the fluorous phase, thus effectively

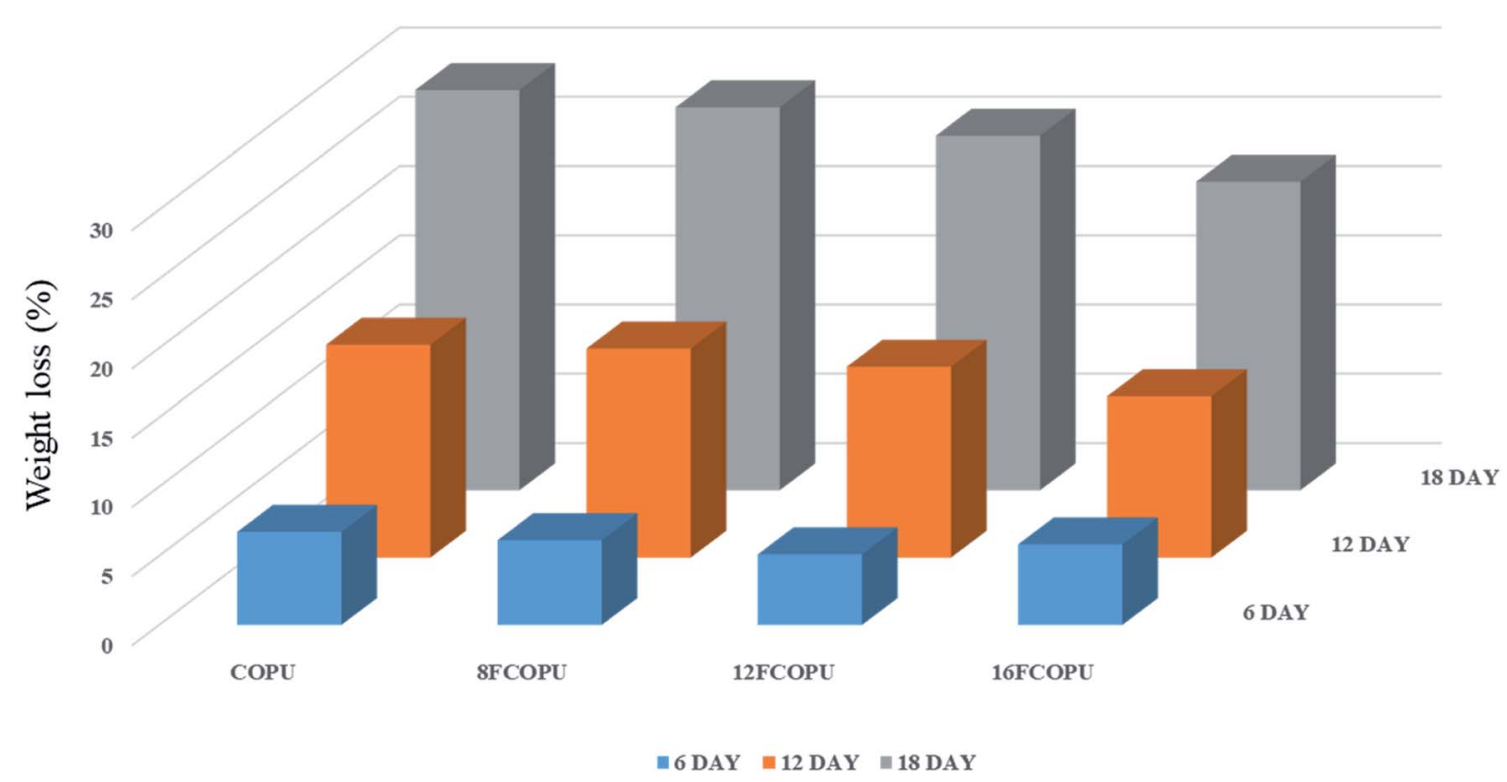

Fig. 14 Weight loss of hydrolytic degradation results of the FCOPUs. 


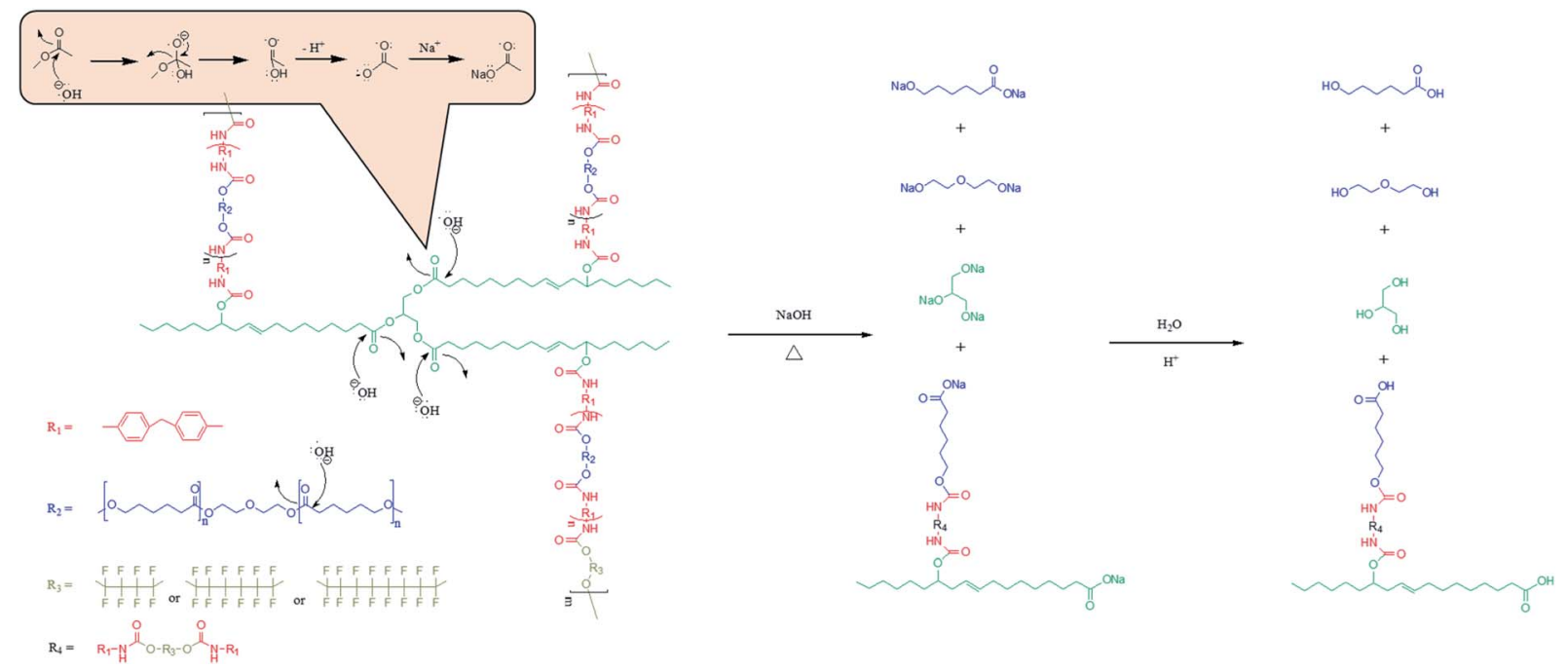

Fig. 15 Degradation mechanism of FCOPUs.

preventing FCOPU degradation by the $\mathrm{NaOH}$ solution. Moreover, the degradation process of the FCOPUs started from the outer layer and gradually toward the inner layer of PUs, without producing any cracks. The result suggested that the FCOPU film stayed undamaged during the entire degradation process until it was degraded completely by the $\mathrm{NaOH}$ solution and verified

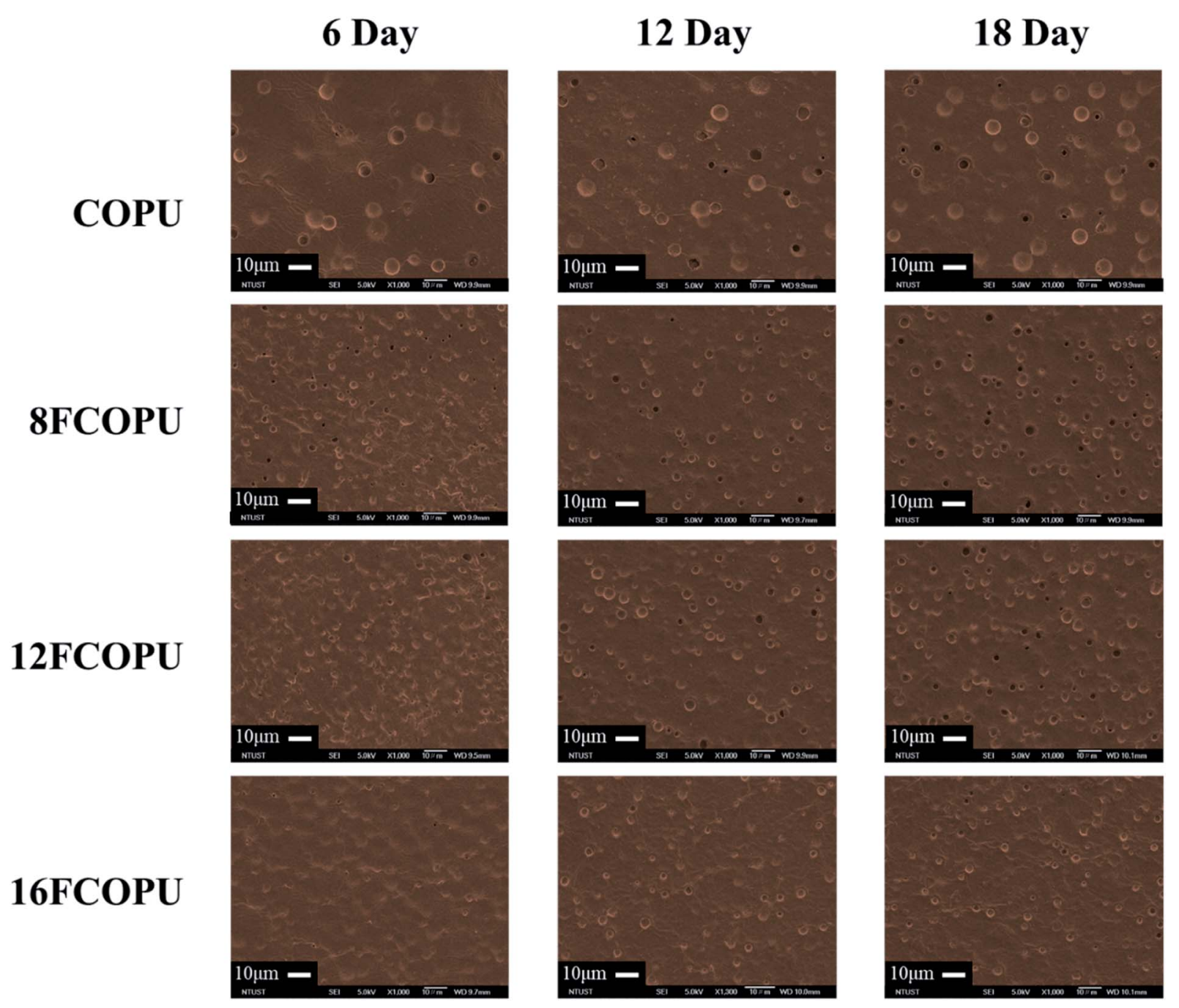

Fig. 16 Scanning electron microscope micrographs of the FCOPUs with hydrolytic degradation for $6,12,18$ days at $45^{\circ} \mathrm{C}$. 
Table 7 Comparison of FCOPUs degradation with previously reported PCL-based or castor oil-based polyurethane with fluorinated segments (or not)

\begin{tabular}{|c|c|c|c|c|c|c|}
\hline Sample name & Solvent & Time (day) & Temp. $\left({ }^{\circ} \mathrm{C}\right)$ & Loss weight (\%) & Morphology & Ref. \\
\hline COPU & $3 \mathrm{wt} \% \mathrm{NaOH}$ & 18 & 45 & 28.88 & Pores & This study \\
\hline 16FCOPU & $3 \mathrm{wt} \% \mathrm{NaOH}$ & 18 & 45 & 22.28 & Pores & This study \\
\hline PCL & Buffer solutions ( $\mathrm{pH} 4)$ & 50 & 37 & $\approx 12$ & Irregular and defects. & 27 \\
\hline OPU & 45 wt $\% \mathrm{NaOH}$ & 7 & $\mathrm{RT}^{a}$ & $\approx 50$ & - & 45 \\
\hline FPU-1 & $45 \mathrm{wt} \% \mathrm{NaOH}$ & 7 & $\mathrm{RT}^{a}$ & $\approx 4$ & - & 45 \\
\hline WPU (castor oil-based) & $1 \mathrm{wt} \% \mathrm{NaOH}$ & 0.5 & 45 & $\approx 21$ & Pores & 47 \\
\hline
\end{tabular}

the potential of the FCOPUs prepared by this study regarding their durability and degradability. Table 7 shows comparison of FCOPUs degradation with previously reported PCL-based or castor oil-based polyurethane with fluorinated segments (or not). It was instructed first that the degradation rate of PCL was higher in base environment than that in acid environment. ${ }^{27}$ It was reported when the fluorine element was introduced into polyurethane, and the degradation stability could be increased significantly. ${ }^{45}$ In the previous report of our laboratory, it was reported that it showed as for linear PCL-based polyurethane with fluorinated segments, after PU/OFHD was immersed in $3 \mathrm{wt} \% \mathrm{NaOH}$ at $45{ }^{\circ} \mathrm{C}$ for 18 days, its weight loss was about 9$15 \%$ with the generation of crack. It was lower than the weight loss $22 \%$ for $16 \mathrm{FCOPU}$ in this study. It might be influenced by the existence of castor oil. Compared to PCL, the degradation rate of castor oil is much higher at base environment. As Li et al. reported when castor oil was used as polyurethane soft segment which was immersed in $1 \mathrm{wt} \% \mathrm{NaOH}$ at $45^{\circ} \mathrm{C}$ and degraded for 0.5 days, the weight loss was as high as $21 \%$. The surface structure of castor oil-based WPU was become the pore without crack. ${ }^{47}$ This appearance was similar to FCOPUs. So, it could be speculated that after the sample of this study was degraded, the generation of pore structure was attributable to the existence of castor oil.

\section{Conclusions}

This study successfully prepared durable, degradable PUs by using MDI, PCL, castor oil, and fluorinated chains, ${ }^{1} \mathrm{H} \mathrm{NMR},{ }^{19} \mathrm{~F}$ NMR, ${ }^{19} \mathrm{~F}-{ }^{19} \mathrm{~F}$ COSY, ${ }^{1} \mathrm{H}^{-19} \mathrm{~F}$ COSY, and HMBC confirmed the successful synthesis of FCOPUs. Using similar molecular weight in all PU samples, we investigated how the length of perfluorinated alkyl segments would affect FCOPUs; the FTIR and XPS curve fitting results revealed that increases in such length increased (8FCOPU to $16 \mathrm{FCOPU}$ ) hydrogen bonding interactions from $47.08 \%$ to $93.28 \%$ and increased the binding energy of C- $\mathrm{F}_{2}$ from 291.81 to $282.15 \mathrm{eV}$. According to these results, an increased number of perfluorinated alkyl segments effectively increased the number of hydrogen bonding interactions of FCOPUs. The AFM result showed that increased hydrogen bonding interactions were associated with higher level of phase separation. Regarding the thermal properties, the TGA, DSC, and DMA results revealed that when the lengths of perfluorinated alkyl segments increased, the numbers of physical crosslinks increased, which increased the thermal decomposition and glass transition temperatures of FCOPUs by approximately $5{ }^{\circ} \mathrm{C}$; additionally, the DMA result suggested that the $\tan \delta$ decreased from 0.650 to 0.591 . These results indicated that a long perfluorinated alkyl chain extender increased the elasticity and decreased the viscosity of FCOPUs. The result was similar to the tensile strength test, which suggested that a long perfluorinated alkyl chain extender increased the stiffness of FCOPU films. Finally, we performed a degradation test using a $3 \mathrm{wt} \% \mathrm{NaOH}$ solution and verified that increasing fluorine content was conducive to slowing down the degradation process and that all samples exhibited circular pores rather than cracks on their surfaces during the degradation process, showing that FCOPUs have durable, degradable properties.

\section{Conflicts of interest}

There are no conflicts to declare.

\section{Acknowledgements}

We acknowledge financial supports from the Ministry of Economic Affairs and the National Science Council (NSC) of Taiwan.

\section{References}

1 M. Liu, T. Zhang, L. Long, R. Zhang and S. Ding, Polym. Degrad. Stab., 2019, 160, 120-125.

2 R. Geyer, J. R. Jambeck and K. L. Law, Sci. Adv., 2017, 3, e1700782.

3 M. A. Elsawy, K. H. Kim, J. W. Park and A. Deep, Renewable Sustainable Energy Rev., 2017, 79, 1346-1352.

4 H. W. Jung, M. K. Yang and R. C. Su, Polym. Degrad. Stab., 2018, 154, 186-194.

5 Y. Tokiwa, B. Calabia, C. Ugwu and S. Aiba, Int. J. Mol. Sci., 2009, 10, 3722-3742. 
6 E. Murray, B. C. Thompson, S. Sayyar and G. G. Wallace, Polym. Degrad. Stab., 2015, 111, 71-77.

7 K. Thirunavukarasu, S. Purushothaman, J. Sridevi, M. Aarthy, M. K. Gowthaman, T. Nakajima-Kambe and N. R. Kamini, Int. Biodeterior. Biodegrad., 2016, 110, 99-107. 8 P. Anbukarasu, D. I. Martínez-Tobón, D. Sauvageau and A. L. Elias, Polym. Degrad. Stab., 2017, 142, 102-110.

9 U. Biermann, W. Friedt, S. Lang, W. Lühs, G. Machmüller, J. O. Metzger, M. Rüsch gen. Klaas, H. J. Schäfer and M. P. Schneider, Angew. Chem., 2000, 112, 2292-2310.

10 K. R. Kunduru, A. Basu, M. Haim Zada and A. J. Domb, Biomacromolecules, 2015, 16, 2572-2587.

11 G. Lligadas, J. C. Ronda, M. Galià and V. Cádiz, Mater. Today, 2013, 16, 337-343.

12 T. M. Crescentini, J. C. May, J. A. McLean and D. M. Hercules, Polymer, 2019, 121624.

13 W. Xian, L. Song, B. Liu, H. Ding, Z. Li, M. Cheng and L. Ma, J. Appl. Polym. Sci., 2018, 135, 45974.

14 C. Tao, Z. Luo, J. Bao, Q. Cheng, Y. Huang and G. Xu, J. Mater. Sci., 2018, 53, 8639-8652.

15 X. Jian, Y. Song, W. Zhou and L. Xiao, Polym. Eng. Sci., 2019, 59, 724-729.

16 A. Niemczyk, A. Piegat, Á. S. Olalla and M. El Fray, Eur. Polym. J., 2017, 93, 182-191.

17 D. Hermida-Merino, B. O. Driscoll, L. R. Hart, P. J. Harris, H. M. Colquhoun, A. T. Slark, C. Prisacariu, I. W. Hamley and W. Hayes, Polym. Chem., 2018, 9, 3406-3414.

18 L. Rueda, B. F. d'Arlas, M. A. Corcuera and A. Eceiza, Polym. Degrad. Stab., 2014, 108, 195-200.

19 S. L. Huang, M. S. Chao, R. C. Ruaan and J. Y. Lai, Eur. Polym. J., 2000, 36, 285-294.

20 P. Alagi, Y. J. Choi and S. C. Hong, Eur. Polym. J., 2016, 78, 46-60.

21 Y. Guo, R. Zhang, Q. Xiao, H. Guo, Z. Wang, X. Li, J. Chen and J. Zhu, Polymer, 2018, 138, 242-254.

22 T. Gurunathan, S. Mohanty and S. K. Nayak, Prog. Org. Coat., 2015, 80, 39-48.

23 M. V. Hormaiztegui, M. I. Aranguren and V. L. Mucci, Eur. Polym. J., 2018, 102, 151-160.

24 S. Gómez-Fernández, L. Ugarte, C. Peña-Rodriguez, M. Á. Corcuera and A. Eceiza, Polym. Degrad. Stab., 2016, 132, 41-51.

25 L. C. Raghunanan, S. Fernandez-Prieto, I. Martínez, C. Valencia, M. C. Sánchez and J. M. Franco, Eur. Polym. J., 2018, 101, 291-303.
26 K. K. Choi, S. H. Park, K. W. Oh and S. H. Kim, Macromol. Res., 2018, 23, 333-340.

27 R. Scaffaro, F. Lopresti and L. Botta, Eur. Polym. J., 2017, 96, 266-277.

28 R. Berger, G. Resnati, P. Metrangolo, E. Weber and J. Hulliger, Chem. Soc. Rev., 2011, 40, 3496-3508.

29 J. W. Li, H. T. Lee, H. A. Tsai, M. C. Suen and C. W. Chiu, Polymers, 2018, 10, 1292.

30 S. K. Su, J. H. Gu, H. T. Lee, C. L. Wu, Y. R. Su and M. C. Suen, J. Polym. Res., 2018, 25, 227.

31 O. Kysilka, M. Rybáčková, M. Skalický, M. Kvíčalová, J. Cvačka and J. Kvíčala, Collect. Czech. Chem. Commun., 2008, 73, 1799-1813.

32 Q. Tang and K. Gao, Int. J. Polym. Anal. Charact., 2017, 22, 569-574.

33 W. Yang, X. Cheng, H. Wang, Y. Liu and Z. Du, Polymer, 2017, 133, 68-77.

34 X. Wang, J. Xu, L. Li, Y. Liu, Y. Li and Q. Dong, Polymer, 2016, 98, 311-319.

35 N. Li, F. Zeng, Y. Wang, D. Qu, W. Hu, Y. Luan, S. Dong, J. Zhang and Y. Bai, RSC Adv., 2017, 7, 30970-30978.

36 F. Yu, L. Cao, Z. Meng, N. Lin and X. Y. Liu, Polym. Chem., 2016, 7, 3913-3922.

37 R. Berger, G. Resnati, P. Metrangolo, E. Weber and J. Hulliger, Chem. Soc. Rev., 2011, 40, 3496-3508.

38 S. Y. Hsu, S. C. Lin, J. A. Wang, C. C. Hu, C. C. M. Ma and D. H. Tsai, Electrochim. Acta, 2019, 296, 427-437.

39 R. Piya, Y. Zhu, A. H. Soeriyadi, S. M. Silva, P. J. Reece and J. J. Gooding, Biosens. Bioelectron., 2019, 127, 229-235.

40 I. Muzammil, Y. Li and M. Lei, Plasma Processes Polym., 2017, 14, 1700053.

41 S. Kerr and F. Y. Naumkin, New J. Chem., 2017, 41, 1357613584.

42 V. P. Swapna, R. Stephen, T. Greeshma, C. Sharan Dev and M. S. Sreekala, Polym. Compos., 2016, 37, 602-611.

43 C. H. Tsou, H. T. Lee, H. A. Tsai, H. J. Cheng and M. C. Suen, Polym. Degrad. Stab., 2013, 98, 643-650.

44 N. Goonoo, A. Bhaw-Luximon, I. A. Rodriguez, D. Wesner, H. Schönherr, G. L. Bowlin and D. Jhurry, Biomater. Sci., 2014, 2, 339-351.

45 N. Li, F. L. Zeng, Y. Wang, D. Z. Qu, C. Zhang, J. Li, J. Z. Huo and Y. P. Bai, Chin. J. Polym. Sci., 2018, 36, 85-97.

46 C. L. Wu, S. H. Chiu, H. T. Lee and M. C. Suen, Polym. Adv. Technol., 2016, 27, 665-676.

47 J. W. Li, W. C. Tsen, C. H. Tsou, M. C. Suen and C. W. Chiu, Polymers, 2019, 11, 1333. 